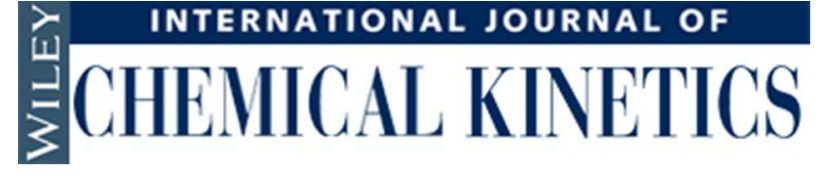

\title{
The ORAC Assay: Mathematical Analysis of the Rate Equations and Some Practical Considerations
}

\begin{tabular}{|r|l|}
\hline Journal: & International Journal of Chemical Kinetics \\
\hline Manuscript ID & KIN-16-0137.R2 \\
\hline Wiley - Manuscript type: & Article \\
\hline Date Submitted by the Author: & n/a \\
\hline Complete List of Authors: & $\begin{array}{l}\text { Arellano, Juan; Instituto de Recursos Naturales y Agrobiologia de } \\
\text { Salamanca, Estrés abiótico; } \\
\text { Mellado-Ortega, Elena; Instituto de Recursos Naturales y Agrobiologia de } \\
\text { Salamanca, Estrés abiótico } \\
\text { Naqvi, K; Norges teknisk-naturvitenskapelige universitet, Physics }\end{array}$ \\
\hline Keywords: & $\begin{array}{l}\text { Antioxidant reactivity, Chini equation, Lie symmetry group theory, ORAC, } \\
\text { Peroxyl radical, von Bertalanffy equation }\end{array}$ \\
\hline &
\end{tabular}




\title{
The ORAC Assay: Mathematical Analysis of the Rate Equations and Some Practical Considerations
}

\author{
Juan B. Arellano ${ }^{a}$, Elena Mellado-Ortega ${ }^{a}$, and K. Razi Naqvi ${ }^{b}$
}

${ }^{a}$ Departamento de Estrés Abiótico. Instituto de Recursos Naturales y Agrobiología de Salamanca (IRNASA-CSIC). Cordel de merinas 52, 37008 Salamanca, Spain

${ }^{\mathrm{b}}$ Department of Physics, Norwegian University of Science and Technology, N-7491

Trondheim, Norway

*Corresponding author: Juan B. Arellano. E-mail: juan.arellano@irnasa.csic.es. Phone: +34923219 606. ORCID: orcid.org/0000-0001-8677-8697 


\section{Abstract}

ORAC (Oxygen Radical Absorbance Capacity), a method widely used for measuring the total antioxidant capacity of biological samples, can also be used for the determination of the relative reactivity of an antioxidant compound $(\mathrm{X}-\mathrm{H})$ by examining the dependence of the rate of consumption of the probe $(\mathrm{P}-\mathrm{H})$ on the concentration of $\mathrm{X}$ $\mathrm{H}$; initial conditions are chosen in such a way that the rate of consumption of the starting reactants may be assumed to follow a drastically simplified kinetic scheme, and the steady state approximation for the concentration of the azo compound peroxyl (ROO') radical is invoked to simplify the analysis. Here we first attempted to find an analytical solution to the coupled first order ordinary differential equations (ODEs) of the minimal ORAC kinetic system, applying Lie symmetry group theory without any precondition. However, the Lie symmetry transformations applied to the Chini equation, which appeared after mathematical transformations, showed that the form of the coefficients of the Chini equation precluded the analytical solution of the minimal ORAC kinetic system through symmetry reduction. Consequently, an approximate analytical solution was sought, valid for the case when the bimolecular rate constant of $\mathrm{X}-\mathrm{H}$ with $\mathrm{ROO}^{\bullet}\left(\right.$ i.e. $k_{x}$ ) was much larger than that of $\mathrm{P}-\mathrm{H}$ with $\mathrm{ROO}^{\bullet}\left(\right.$ i.e. $\left.k_{p}\right)$. Using numerical solution of the original set of ODEs of the ORAC kinetic system, the quality of the approximate solution was inspected under conditions that correspond to those employed in several ORAC methods together with a low initial concentration of the azo compound radical initiator. The simulations allowed us to conclude that the approximate analytical solution of the ODEs of the minimal ORAC kinetic system was not entirely devoid of academic interest, but its applicability was restricted to conditions where both $k_{x}>>k_{p}$ and the initial concentration of X-H was higher than that of $\mathrm{P}-\mathrm{H}$. 
1

2

3

4

5

6

7

8

9

10

11

12

13

14

15

16

17

18

19

20

21

22

23

24

25

26

27

28

29

30

31

32

33

34

35

36

37

38

39

40

41

42

43

44

45

46

47

48

49

50

51

52

53

54

55

56

57

58

59

60

Keywords: Antioxidant reactivity, Chini equation, Lie symmetry group theory, ORAC, Peroxyl radical, von Bertalanffy equation.

John Wiley \& Sons, Inc. 


\section{Introduction}

The ORAC (Oxygen Radical Absorbance Capacity) assay is widely used for determining the "total" antioxidant capacity (TAC) of biological samples, particularly those possessing nutritional, pharmaceutical and clinical interest. One variant, first developed by Glazer, ${ }^{1}$ entails monitoring the loss in the fluorescence emission intensity of a fluorescent probe $(\mathrm{P}-\mathrm{H})$ that undergoes hydrogen atom transfer with tertiary peroxyl $\left(\mathrm{ROO}^{\circ}\right.$ ) radicals. The $\mathrm{ROO}^{\circ}$ radicals are produced in the assay medium by thermolysis of an azo compound ( $\mathrm{R}-\mathrm{N}=\mathrm{N}-\mathrm{R}$ ) whose carbon-centered radical rapidly reacts with dissolved oxygen. An antioxidant compound $(\mathrm{X}-\mathrm{H})$ present in the assay medium competes with $\mathrm{P}-\mathrm{H}$ for $\mathrm{ROO}^{\circ}$ radicals, slowing down the loss of the fluorescence emission intensity of P-H. The measurements are usually given as standard equivalents, and the values depend on the concentration and reactivity of the antioxidant, or a mixture thereof. ${ }^{2,3}$ In addition to the fluorescence-based assay, other ORAC methods employing EPR or spectrophotometric probes have been developed in the last few years. ${ }^{4-6}$ Despite the apparent simplicity of the ORAC reaction scheme (see below) and the advantages of the ORAC assay in comparison with its rivals, Schaich and coworkers ${ }^{7}$ have outlined the complexity of this assay and the limitations and caveats that should be borne in mind in its execution. Moreover, LC-MS/MS and EPR studies provided evidence for accumulation of alkoxyl $\left(\mathrm{RO}^{\circ}\right)$ radicals after the formation of $\mathrm{ROO}^{\circ}$ radicals by thermolysis or photolysis of 2,2'-azobis(2-amidinopropane) dihydrochloride (AAPH), the most widely used initiator of $\mathrm{ROO}^{\circ}$ radicals in ORAC assays. ${ }^{8,9}$ In contrast to AAPH, the incubation of other azo compounds, such as 2,2'azobis(2,4-dimethylvaleronitrile) (AMVN), with spin traps produce mainly ROO• radical spin adducts, suggesting that the chemical structure of the azo compounds has a 
direct effect on the rate of the self-reaction of ROO ${ }^{\circ}$ radicals. ${ }^{9}$ Whereas fluorescein (a commonly used fluorescent probe) mainly reacts with $\mathrm{RO}^{\circ}$ radicals, the spectrophotometric probe pyrogallol red totally traps $\mathrm{ROO}^{\circ}$ radicals in addition to $\mathrm{RO}^{\bullet}$ radicals at the concentration employed in the ORAC method. ${ }^{10}$ As a consequence of the side reaction of $\mathrm{P}-\mathrm{H}$ with $\mathrm{RO}^{\circ}$ radicals, the use of the ORAC assay to evaluate the antioxidant capacity of compounds to trap $\mathrm{ROO}^{\circ}$ radicals has been called into question. The minimal ORAC kinetic system consists of one apparent first order step and two second order reactions following a consecutive-parallel cascade with three starting reactants:

$$
\begin{aligned}
& \mathrm{R}-\mathrm{N}=\mathrm{N}-\mathrm{R} \underset{\mathrm{O}_{2}, \text { heat }}{\longrightarrow} 2 \mathrm{ROO}^{\circ}+\mathrm{N}_{2} \\
& \mathrm{ROO}^{\circ}+\mathrm{P}-\mathrm{H} \stackrel{k_{p}}{\longrightarrow} \mathrm{ROOH}+\mathrm{P}^{\bullet} \\
& \mathrm{ROO}^{\circ}+\mathrm{X}-\mathrm{H} \stackrel{k_{x}}{\longrightarrow} \mathrm{ROOH}+\mathrm{X}^{\cdot}
\end{aligned}
$$

where $\mathrm{R}-\mathrm{N}=\mathrm{N}-\mathrm{R}, \mathrm{ROO}^{\circ}, \mathrm{P}-\mathrm{H}$ and $\mathrm{X}-\mathrm{H}$ respectively stand for the azo compound, the tertiary azo compound-derived peroxyl radical, the probe and the antioxidant, which can be either any antioxidant compound or Trolox, the latter usually employed as standard in the ORAC assay; $k_{a}, k_{p}$ and $k_{x}$ represent the apparent first order and second order rate constants of the reactions R.1, R.2 and R.3, respectively. Here $k_{a} \approx e k_{d}$, where $k_{d}$ stands for the rate constant for the unimolecular dissociation of $\mathrm{R}-\mathrm{N}=\mathrm{N}-\mathrm{R}$ and $e$ is the efficiency of free $\mathrm{ROO}^{\bullet}$ radical production. ${ }^{9,11}$.

As stated above, $\mathrm{RO}^{\circ}$ radicals can be indeed formed in the ORAC assay and react rapidly with X-H in the reaction mixture; however, the reactions R.4-R.6 will not be considered in this study for the sake of simplicity. If the initial concentration of the 
azo compound radical initiator is low, the $\mathrm{ROO}^{\circ}$ radical self-reaction will not compete significantly with R.2 and R.3 and the RO ${ }^{\bullet}$ radicals will be present at a concentration low enough to justify the neglect of the $\mathrm{RO}^{\bullet}$ radical self-reaction.

$$
\begin{aligned}
& 2 \mathrm{ROO}^{\circ} \longrightarrow \mathrm{ROOOOR} \\
& \mathrm{ROOOOR}^{\longrightarrow} 2 \mathrm{RO}^{\circ}+\mathrm{O}_{2} \\
& \mathrm{ROO}^{\circ} \longrightarrow \mathrm{ROOR}
\end{aligned}
$$

Apart from standard TAC measurements, the ORAC assay is also applied to analyse the relative reactivity of X-H. When this is the goal, Stern-Volmer-like plots are usually employed to determine the relationship between the ratio of the consumption rate of $\mathrm{P}-\mathrm{H}$ (R.2) in the absence and the presence of X-H and the ratio $[\mathrm{P}-\mathrm{H}] /[\mathrm{X}-\mathrm{H}]$ ${ }^{6,12,13}$ In this type of analysis, either $[\mathrm{P}-\mathrm{H}]$ is kept high enough to warrant the assumptions that the consumption of $[\mathrm{P}-\mathrm{H}]$ follows a zero order reaction and that of the azo compound a first order reaction; or the $\mathrm{ROO}^{\circ}$ radical production is kept under a constant flux. Likewise, the extent of the initial plateau (or induction time region) of $[\mathrm{P}-\mathrm{H}]$ can be used to examine the relative reactivity of $\mathrm{X}-\mathrm{H}$ when the initial concentration of the azo compound is low and there is a steady state formation of ROO radicals. ${ }^{14}$ In this latter case the induction time is proportional to the ratio between $[\mathrm{X}-\mathrm{H}]$ and the rate of the $\mathrm{ROO}^{\circ}$ radical formation. ${ }^{11}$

Although the ORAC assay has been used extensively, we could find no published attempts to solve mathematically the minimal ORAC kinetic system. We thus explored whether the set of linear first order ordinary differential equations (ODEs) of the minimal ORAC kinetic system could be solved through mathematical analysis, 
which was in fact the main goal of the current study. In our analysis, mathematical transformations applied to the ODEs of the minimal ORAC kinetic system resulted in the non-autonomous Chini equation, ${ }^{15}$ an ODE that is polynominal in the dependent variable $y$, i.e. $d y / d x=f_{n}(x) y^{n}+f_{1}(x) y+f_{0}(x)$, where $n$ is a rational number and the coefficients $f_{n}(x), f_{1}(x)$ and $f_{0}(x)$ are functions of the independent variable $x$. Applying Lie symmetry group theory ${ }^{16,17}$ to reduce the non-autonomous Chini equation to the autonomous equation, we reached the conclusion that the particular mathematical form of the coefficients of this ODE made the minimal ORAC kinetic system unsolvable through Lie symmetry reduction. However, a closer inspection of the nonautonomous Chini equation and the dependence of $n$ on $k_{x}$ and $k_{p}$ led us to search for an approximate analytical solution of the ODEs of the minimal ORAC kinetic when the restriction $k_{x}>>k_{p}$ was imposed. The goodness of the approximation was tested by comparing the numerical solution of the ODEs of the minimal ORAC kinetic applying the Runge-Kutta method with the approximate analytical solution of the ODEs we achieved in this study. The parameters (i.e. the initial concentrations of reactants and rate constants) and the range of values they can take were those employed in several ORAC methods, except that the initial concentration of the azo compound radical initiator was kept low to make the contribution of R.4-R.6 negligible.

\section{Material and methods}

The Runge-Kutta method was applied to solve numerically the ODEs of the minimal ORAC kinetic system and to compile sets of data points for the selected input 
parameters. These sets of data points were then used to evaluate the approximate analytical solution we achieved in this study.

The computer algebra system Wolfram Mathematica ${ }^{18}$ (version 10.3) was used to program a script for solving numerically the ODEs of the R.1-R.3 reactions (online resource 1). The script was run to plot the numerical solutions of the ODEs shown in Figures 1-4 and S1-S2. The "ParametricNDSolve" command, together with other graphical and table commands, was programmed in such a way that the user could arbitrarily modify the time and the parameters (i.e. the values for initial concentrations and rate constants) in the script. The numerical values for $[\mathrm{X}-\mathrm{H}]_{0}$ and $[\mathrm{P}-\mathrm{H}]_{0}$, chosen in conformity with those usually reported in ORAC assays, were in the range of $\mu \mathrm{M}$ and (sub) $\mu \mathrm{M}$, respectively. ${ }^{3,5,12,19,20}$ In order to be able to ignore reactions R.4-R.6, the initial concentration of the azo compound radical initiator, $[\mathrm{R}-\mathrm{N}=\mathrm{N}-\mathrm{R}]_{0}$, was chosen to be a few tens of $\mu \mathrm{M}$, about two order of magnitude lower than those values usually reported in ORAC assays. A value of $\sim 2.4 \times 10^{-6} \mathrm{~s}^{-1}$ was used for the dissociation rate of the azo compound radical initiator. ${ }^{8}$ The rate constants $k_{x}$ and $k_{p}$ were estimated to range between $10^{4}-10^{7} \mathrm{M}^{-1} \mathrm{~s}^{-1}$ and $<10^{3}-10^{4} \mathrm{M}^{-1} \mathrm{~s}^{-1}$, respectively, and the $k_{x} / k_{p}$ ratio to vary by $1-3$ orders of magnitude..$^{5,6,13,21-23}$ The mathematical steps to reach the approximate analytical solution of the ODEs of the minimal ORAC kinetic system are explained in the Results and Discussion section.

The goodness of the approximation introduced in the analytical solution of the ODEs of the minimal ORAC kinetic system was evaluated through the determination of the percentage of the coefficient of variation $(\mathrm{CV})$ of the root mean square deviation (RMSD) of the difference between the numerical and analytical solutions of the ODEs: 


$$
\mathrm{CV}(\mathrm{RMSD}) \%=\frac{\sqrt{\frac{1}{n} \sum_{i=1}^{n}\left(y_{i}-Y_{i}\right)^{2}}}{\bar{y}} \times 100
$$

where $y_{i}$ is the $i$ th numerical value of the concentration of a reactant $\left(\mathrm{ROO}^{\circ}, \mathrm{X}-\mathrm{H}\right.$ or $\mathrm{P}-$ $\mathrm{H})$ at time $t_{i}$ and $Y_{i}$ is the $i$ th analytical value of the concentration of the same reactant at the same time, and $\bar{y}$ is the mean value of the concentration of the reactant in the time interval under study. The analysis of the CV(RMSD)\% over time was performed until $[\mathrm{P}-\mathrm{H}]$ reached a value of approximately $0.1 \%$ of $[\mathrm{P}-\mathrm{H}]_{0}$. The time increments were selected to make $n=200$. The lower the value of CV(RMSD) $\%$, the better is the fit between the numerical and analytical solutions of the ODEs. The script of approximate analytical solution of the minimal ORAC kinetic system is shown in the online resource 2. This script was run to plot the curves corresponding with the approximate analytical solutions of the ODEs shown in Figures 3 and 4.

\section{Results and Discussion}

Numerical simulations of the minimal ORAC kinetic system

The first order ODEs of the minimal ORAC kinetic system can be represented as follows:

$$
-\frac{d[\mathrm{R}-\mathrm{N}=\mathrm{N}-\mathrm{R}]}{d t}=k_{a}[\mathrm{R}-\mathrm{N}=\mathrm{N}-\mathrm{R}]
$$




$$
\begin{aligned}
& \frac{d\left[\mathrm{ROO}^{\bullet}\right]}{d t}=2 k_{a}[\mathrm{R}-\mathrm{N}=\mathrm{N}-\mathrm{R}]-\left(k_{x}[\mathrm{X}-\mathrm{H}]+k_{p}[\mathrm{P}-\mathrm{H}]\right)\left[\mathrm{ROO}^{\bullet}\right] \\
& -\frac{d[\mathrm{P}-\mathrm{H}]}{d t}=k_{p}\left[\mathrm{ROO}^{\bullet}\right][\mathrm{P}-\mathrm{H}] \\
& -\frac{d[\mathrm{X}-\mathrm{H}]}{d t}=k_{x}\left[\mathrm{ROO}^{\bullet}\right][\mathrm{X}-\mathrm{H}]
\end{aligned}
$$

At $t=0$, the concentration of the starting and intermediate reactants are taken to be $[\mathrm{R}-\mathrm{N}=\mathrm{N}-\mathrm{R}]=[\mathrm{R}-\mathrm{N}=\mathrm{N}-\mathrm{R}]_{0},\left[\mathrm{ROO}^{\bullet}\right]=0,[\mathrm{X}-\mathrm{H}]=[\mathrm{X}-\mathrm{H}]_{0}$ and $[\mathrm{P}-\mathrm{H}]=[\mathrm{P}-\mathrm{H}]_{0}$. Figure 1 shows a numerical simulation of standard curves representing the changes in the concentration profile (or the fluorescence/absorbance signal) of $\mathrm{P}-\mathrm{H}$ over time in an ORAC assay using different values for $[\mathrm{X}-\mathrm{H}]_{0}$. In the presence of the azo compound radical initiator and $\mathrm{X}-\mathrm{H}$, the signal of $\mathrm{P}-\mathrm{H}$ displays a plateau followed by decay when $[\mathrm{X}-\mathrm{H}]$ starts reaching values close to zero. The extent of the curve plateau (or induction time region) is proportional to $[\mathrm{X}-\mathrm{H}]_{0}$ and is nearly flat when the reactivity of $\mathrm{X}-\mathrm{H}$ (i.e. $k_{x}$ ) is high. ${ }^{14,20,24}$ When this occurs the reaction of $\mathrm{ROO}^{\bullet}$ radicals with $\mathrm{X}-\mathrm{H}$ is dominant and $\mathrm{P}-\mathrm{H}$ is minimally consumed in the induction time region. The reactivity of X-H depends on the bond dissociation energy of the hydrogen atom, the solvent, the number of hydrogen donor moieties, ${ }^{23}$ and probably on the interaction between $\mathrm{X}-\mathrm{H}$ if there are several in the reaction mixture. ${ }^{20}$

The flatness of the curve plateau becomes less prominent or even hardly noticeable when X-H shows poor reactivity (i.e. $k_{x}$ approaches $k_{p}$ ). In this latter case, both $\mathrm{X}-\mathrm{H}$ and $\mathrm{PH}$ compete for $\mathrm{ROO}^{\bullet}$ radicals in the induction time region (Fig. S1). Similar results have also been described when a large fraction of $\mathrm{ROO}^{\circ}$ radicals is consumed rapidly by $\mathrm{P}-\mathrm{H}$, particularly under experimental conditions where the ratio 
$[\mathrm{X}-\mathrm{H}]_{0} /[\mathrm{P}-\mathrm{H}]_{0}$ is low and $k_{x}$ and $k_{p}$ are of similar order of magnitude. ${ }^{6,20}$ Figure S2 (panels A and B) shows how an increase in $[\mathrm{P}-\mathrm{H}]_{0}$ affects the curve plateau while $[\mathrm{X}-\mathrm{H}]_{0}$ remains constant. The changes in this region become more evident if, together with an increase in $[\mathrm{P}-\mathrm{H}]_{0}$, there is a decrease in the reactivity of $\mathrm{X}-\mathrm{H}$. The loss in curve flatness corresponds with an increase in the consumption rate of $[\mathrm{P}-\mathrm{H}]$ in the induction time region, which goes together with a decrease in the maximum consumption rate of $[\mathrm{P}-\mathrm{H}]$ in the decay region (Figure $\mathrm{S} 2$, panels $\mathrm{C}$ and $\mathrm{D}$ ).

If the steady state approximation (SSA) is applied to [ROO ${ }^{\circ}$ ] by setting the right-hand side of (Eq.2) to zero (online resource 3), one finds that $\Sigma$, the sum of [P-H] and $[\mathrm{X}-\mathrm{H}]$, comes out to be $\Sigma(t)=\Sigma(0)-2[\mathrm{R}-\mathrm{N}=\mathrm{N}-\mathrm{R}]_{0}\left[1-\exp \left(-k_{a} t\right)\right]$, where $\Sigma(0)=[\mathrm{X}-\mathrm{H}]_{0}+[\mathrm{P}-\mathrm{H}]_{0}$. Under conditions where $100 k_{p}[\mathrm{P}-\mathrm{H}]<k_{x}[\mathrm{X}-\mathrm{H}],{ }^{12}$ the application of SSA seems to be valid at the beginning of the reaction. In the induction time region, $\mathrm{X}-\mathrm{H}$ is at high concentration and efficiently reacts with $\mathrm{ROO}^{\circ}$. However, the SSA for $\left[\mathrm{ROO}^{\circ}\right]$ is not valid when $[\mathrm{X}-\mathrm{H}]$ starts reaching values close to zero and [P-H] is still close to the initial value (Fig. 2). In this particular region and beyond it, the change in $\left[\mathrm{ROO}^{\circ}\right]$ over time cannot be neglected and the condition $k_{p}[\mathrm{P}-\mathrm{H}]+k_{x}[\mathrm{X}-\mathrm{H}]>>2 k_{a}[\mathrm{AAPH}]$ does not hold. In the decay region, $[\mathrm{P}-\mathrm{H}]$ decreases with a consumption rate that depends on the instant concentration of $\mathrm{P}-\mathrm{H}$ and $\mathrm{ROO}$ • provided that the R.4-R.6 reactions do not compete. Representative profiles of the consumption rate of $[\mathrm{P}-\mathrm{H}]$ in the decay region are shown in Figure $\mathrm{S} 2$ (panel C and D). Such changes could not be observed in a kinetic analysis if the SSA was applied to $\left[\mathrm{ROO}^{\circ}\right]$. 
Consequently, we intended to solve through mathematical analysis, and without any precondition, the ODEs of the minimal ORAC kinetic system with the aim of achieving a better understanding of the functional dependence of the concentration profile of the ORAC reactants on time, initial reactant concentrations and rate constants.

The Chini invariant condition precludes the analytical solution of the minimal ORAC kinetic system

Following the minimal ORAC kinetic system, the concentration of the azo compound, $\mathrm{ROO}^{\circ}, \mathrm{X}-\mathrm{H}$ and $\mathrm{P}-\mathrm{H}$ at time $t$ can be represented as:

$[\mathrm{R}-\mathrm{N}=\mathrm{N}-\mathrm{R}]=[\mathrm{R}-\mathrm{N}=\mathrm{N}-\mathrm{R}]_{0}-x,\left[\mathrm{ROO}^{\bullet}\right]=2 x-y-z,[\mathrm{X}-\mathrm{H}]=[\mathrm{X}-\mathrm{H}]_{0}-y,[\mathrm{P}-\mathrm{H}]=[\mathrm{P}-\mathrm{H}]_{0}-z$

, where $x, y$ and $z$ stand for the reacted concentration of $\mathrm{R}-\mathrm{N}=\mathrm{N}-\mathrm{R}, \mathrm{X}-\mathrm{H}$ and $\mathrm{P}-\mathrm{H}$ at time $t$, respectively.

For the sake of clarity, the initial concentration of the starting reactants will be abbreviated as $\mathrm{a}_{0}=[\mathrm{R}-\mathrm{N}=\mathrm{N}-\mathrm{R}]_{0}, \mathrm{x}_{0}=[\mathrm{X}-\mathrm{H}]_{0}$ and $\mathrm{p}_{0}=[\mathrm{P}-\mathrm{H}]_{0}$ in the mathematical expressions of the ODEs. The solution of Eq. 1 is straightforward and the ratio between $[\mathrm{P}-\mathrm{H}] /[\mathrm{X}-\mathrm{H}]$ can be obtained if Eq.3 is divided by Eq.4 and the resulting equation is integrated. After these first steps, one can express Eq.4 as a function of $y$ and $t$.

$$
\begin{aligned}
& -\frac{d[\mathrm{X}-\mathrm{H}]}{d t}=k_{x}\left[\mathrm{ROO}^{\circ}\right][\mathrm{X}-\mathrm{H}] \\
& -\frac{d\left(\mathrm{x}_{0}-y\right)}{d t}=k_{x}(2 x-y-z)\left(\mathrm{x}_{0}-y\right)
\end{aligned}
$$




$$
\frac{d y}{d t}=k_{x}\left[2 \mathrm{a}_{0}\left(1-e^{-k_{a} t}\right)-y-\left(\mathrm{p}_{0}-\mathrm{p}_{0}\left(\frac{\mathrm{x}_{0}-y}{\mathrm{x}_{0}}\right)^{k_{p} / k_{x}}\right)\right]\left(\mathrm{x}_{0}-y\right)
$$

If the transformations $y=\mathrm{x}_{0}-1 / v, \lambda_{1}=\frac{2 \mathrm{a}_{0}-\mathrm{x}_{0}-\mathrm{p}_{0}}{2 \mathrm{a}_{0}}, \lambda_{n}=\frac{\mathrm{p}_{0} \mathrm{x}_{0}^{-k_{p} / k_{x}}}{2 \mathrm{a}_{0}}$, $n=1-\frac{k_{p}}{k_{x}}, \tau=e^{-k_{a} t}$ and $\kappa=\frac{2 \mathrm{a}_{0} k_{x}}{k_{a}}$ are applied to $d y / d t$, it can be rearranged as:

$$
\frac{d v}{d \tau}=-\frac{\kappa \lambda_{n}}{\tau} v^{n}-\kappa\left(\frac{\lambda_{1}}{\tau}-1\right) v-\frac{\kappa}{2 \mathrm{a}_{0} \tau}
$$

This ODE is referred to as the Chini equation, ${ }^{15}$ which is generally represented as:

$$
\frac{d v}{d \tau}=F(\tau, v)=f_{n}(\tau) v^{n}+f_{1}(\tau) v+f_{0}(\tau)
$$

where $n$ is a rational number and, $f_{n}(\tau), f_{1}(\tau)$ and $f_{0}(\tau)$ are functions of the independent variable $\tau$. If Eq.5 and Eq. 6 are compared the following relationships are straightforward:

$$
n=1-\frac{k_{p}}{k_{x}}, f_{n}(\tau)=-\frac{\kappa \lambda_{n}}{\tau}, f_{1}(\tau)=-\kappa\left(\frac{\lambda_{1}}{\tau}-1\right) \text { and } f_{0}(\tau)=-\frac{\kappa}{2 \mathrm{a}_{0} \tau}
$$

To solve the Chini equation (Eq.6), one can appeal to Lie group analysis. ${ }^{16,17}$ In brief, this method is used to obtain the Lie point symmetry generator(s), $X_{i}$, that leave(s) the differential equation invariant after a transformation. A transformation with 
a symmetry generator $X=\xi(\tau, v) \frac{\partial}{\partial \tau}+\eta(\tau, v) \frac{\partial}{\partial v}$ is used to solve first order ODEs,

where the infinitesimals $\xi$ and $\eta$ are assumed to be linear in $v$, of the form

$\xi(\tau, v)=F_{1}(\tau) v+F_{0}(\tau)$ and $\eta(\tau, v)=G_{1}(\tau) v+G_{0}(\tau)$. The arbitrary functions $F_{i}(\tau)$ and

$G_{i}(\tau)$ can be obtained from the determining equation of the first order ODE when the

coefficients of the powers of $v$ are equal to zero.

$\frac{\partial \eta(\tau, v)}{\partial \tau}+\left(\frac{\partial \eta(\tau, v)}{\partial v}-\frac{\partial \xi(\tau, v)}{\partial \tau}\right) F(\tau, v)+\frac{\partial \xi(\tau, v)}{\partial v} F(\tau, v)^{2}-\left(\frac{\partial F(\tau, v)}{\partial \tau} \xi+\frac{\partial F(\tau, v)}{\partial v} \eta\right)=0$

In this particular case, one reaches that $F_{1}(\tau)$ and $G_{0}(\tau)$ are equal to zero and the remaining equations to be solved are of the form:

$G_{1}(\tau) f_{0}(\tau)-\frac{d F_{0}(\tau)}{d \tau} f_{0}(\tau)-\frac{d f_{0}(\tau)}{d \tau} F_{0}(\tau)=0$

$(1-n) G_{1}(\tau) f_{n}(\tau)-\frac{d F_{0}(\tau)}{d \tau} f_{n}(\tau)-\frac{d f_{n}(\tau)}{d \tau} F_{0}(\tau)=0$

$\frac{d G_{1}(\tau)}{d \tau}+\frac{d F_{0}(\tau)}{d \tau} f_{1}(\tau)+\frac{d f_{1}(\tau)}{d \tau} F_{0}(\tau)=0$

The system is solvable when the ratio $G_{1}(\tau) / F_{0}(\tau)=-H^{\prime}(\tau) / H(\tau)$, where $H(\tau)$ is a new arbitrary function of $\tau \cdot{ }^{25}$ Applying the former ratio, the equations 7 a and $7 b$ give: 
$f_{0}(\tau)=\frac{c_{1}}{F_{0}(\tau) H(\tau)}$ and $f_{n}(\tau)=\frac{c_{2}}{c_{1}} f_{0}(\tau) H(\tau)^{n}$, where $c_{1}$ and $c_{2}$ are integration constants.

If the ratio $\left(f_{0}(\tau) / f_{n}(\tau)\right)^{1 / n}$ is called $S$, we reach that $G_{1}(\tau) / F_{0}(\tau)=S^{\prime} / S$. Additionally, Eq.7c gives $S^{\prime}-f_{1}(\tau) S=k f_{0}(\tau)$ if one first integrates it and the resulting equation is divided by $F_{0}(\tau)$, where $k$ is an arbitrary integration constant. Since now the arbitrary functions $F_{i}(\tau)$ and $G_{i}(\tau)$ are known the infinitesimal can be respectively expressed as:

$\xi(\tau, v)=c_{1} S / f_{0}(\tau)$ and $\eta(\tau, v)=c_{1} S^{\prime} v / f_{0}(\tau)$

So at this point, the linear transformation to solve the Chini equation implies, first, $f_{n}(\tau)$ and $f_{1}(\tau)$ are determined by $f_{0}(\tau)$ and, second, the Chini invariant condition $(k)$ is independent of $\tau$. The Chini invariant condition can be re-written as:

$$
k^{n}=\left(\frac{S^{\prime}-f(\tau)_{1} S}{f_{0}(\tau)}\right)^{n}=n^{-n} f_{0}(\tau)^{-2 n-1} f_{n}(\tau)^{-n-1}\left(\frac{d f_{0}(\tau)}{d \tau} f(\tau)_{n}-f_{0}(\tau) \frac{d f_{n}(\tau)}{d \tau}-n f_{0}(\tau) f_{1}(\tau) f_{n}(\tau)\right)^{n}
$$

If one checks the Chini invariant condition, one reaches the conclusion that the ORAC kinetic system does not fulfil it. Actually, $k$ depends on $\tau$ in the ORAC kinetic system when the coefficients of Eq.5 and their respective first derivative functions are substituted in the above equation. This means that there is no need to continue with the algorithm of Lie's method of symmetries to obtain the canonical coordinates $(r, \mathrm{~s})$ that 
transform the Chini equation, $d v / d \tau=F(\tau, v)$, into the autonomous equation, $d r / d s=\Phi(r)$.

Interestingly, an equivalent symmetry analysis can be carried out if Eq.5 is considered to be a particular case of the von Bertalanffy equation — an ODE usually applied to simulations of general growth-decay systems - following the insightful study by Edwards and Anderssen (2015). ${ }^{26}$ It is worth noting that the Chini equation can be derived from the von Bertalanffy equation when the power of $v$ in the term $f_{1}(\tau) v$ is equal to 1 and a forcing term, i.e. $f_{0}(\tau)$, is added. ${ }^{26}$ From the determining equation of the von Bertalanffy equation one also reaches that $F_{1}(\tau)$ and $G_{0}(\tau)$ are equal to zero, but $G_{1}(\tau)$ is an arbitrary integration constant $\left(a_{1}\right)$ and consequently $d G_{1}(\tau) / d \tau=0$.

Nevertheless, the ratio $G_{1}(\tau) / F_{0}(\tau)=S^{\prime} / S$ also applies to the von Bertalanffy equation and the constraints between $f_{n}(\tau), f_{1}(\tau)$ and $f_{0}(\tau)$ still stand.

$$
\frac{G_{1}(\tau)}{F_{0}(\tau)}=\frac{S^{\prime}}{S}=-\frac{1}{n}\left(\frac{1}{f_{n}(\tau)} \frac{d f_{n}(\tau)}{d \tau}-\frac{1}{f_{0}(\tau)} \frac{d f_{0}(\tau)}{d \tau}\right)=\frac{a_{1}}{F_{0}(\tau)}=\frac{a_{1} f_{0}(\tau)}{a_{1} \int f_{0}(\tau) d \tau+c_{1}}
$$

In conclusion, we reach a situation where the Lie point symmetries to solve the Chini equation or the von Bertalanffy equation cannot be applied to the minimal ORAC kinetic system and, consequently, other alternatives must be sought. Additionally, it is also important to stress that attempts to solve analytically more complex reaction kinetic systems of the ORAC assay, where the self-reactions of $\mathrm{ROO}^{\circ}$ and $\mathrm{RO}^{\circ}$ radicals (R.4-R.6) or the reaction of $\mathrm{RO}^{\circ}$ radicals with $\mathrm{P}-\mathrm{H}$ and $\mathrm{X}-\mathrm{H}$ were included, have been addressed in this study without success. More complex reaction kinetic systems bring about ODE systems with additional differential equation(s) and new terms in Eq.2-Eq.4 
that do not allow to reach functions of the form of Eq. 6 by substitution, where only a dependent variable appears.

The ORAC kinetic system can be solved if $k_{x}>>k_{p}$

If Eq. 5 is inspected carefully one observes that the power of $v$ is a rational number that can be negative or positive $(n \leq 1)$ depending on the ratio between $k_{p}$ and $k_{x}$. In the ORAC assay, the reactivity of $\mathrm{X}-\mathrm{H}$ to trap $\mathrm{ROO}^{\circ}$ radicals is expected to be higher than that of $\mathrm{P}-\mathrm{H}$ (i.e. $k_{x}>k_{p}$ ) and so the $n=1-k_{p} / k_{x}$ value to range between $0<n<1$. In the event that $k_{x}<k_{p}$ and so $n<0, \mathrm{X}-\mathrm{H}$ is of poor reactivity to trap $\mathrm{ROO}^{\circ}$ radicals and this case will not be considered in the following analysis. So here we propose to check the goodness of an approximation where $k_{x} \gg k_{p}$ and consequently $v^{1-k_{p} / k_{x}} \approx v$ to solve Eq.5 through mathematical analysis. In the particular event that $k_{x}=k_{p}$ and so $n=0$, the ORAC kinetic system could in fact be treated as if it was a system with a (pseudo)first order reaction accompanied by only one bimolecular reaction. ${ }^{27,28}$

With $k_{x}>k_{p}$, Eq.5 can be re-written as follows:

$$
\frac{d \nu}{d \tau}+\kappa\left(\frac{\lambda}{\tau}-1\right) \nu=-\frac{\kappa}{2 \mathrm{a}_{0} \tau}, \text { where } \lambda=\lambda_{1}+\lambda_{n} \approx \frac{2 \mathrm{a}_{0}-\mathrm{x}_{0}}{2 \mathrm{a}_{0}}
$$

Now, Eq. 8 is a non-homogenous first order ODE that can be solved easily.

Before it, we have to keep in mind that, first, the initial conditions imply that $v_{0}=1 / \mathrm{x}_{0}$ 
and $\tau_{0}=1$ and, second, the transformation $\zeta=\kappa \tau$ reduces the integral $\int_{1}^{\tau} \tau^{\lambda \kappa-1} e^{-\kappa \tau} d \tau$, which appears in the solution of Eq.8, to a lower Gamma function $(\gamma)$ of the form:

$$
\int_{1}^{\tau} \tau^{\lambda \kappa-1} e^{-\kappa \tau} d \tau=\kappa^{-\lambda \kappa}\left[\int_{0}^{\kappa \tau} \zeta^{\lambda \kappa-1} e^{-\zeta} d \zeta-\int_{0}^{\kappa} \zeta^{\lambda \kappa-1} e^{-\zeta} d \zeta\right]=\kappa^{-\lambda \kappa} \gamma(\lambda \kappa, \kappa \tau, \kappa)
$$

The application of the above initial conditions and transformation gives:

$$
v=e^{\kappa \tau} \tau^{-\kappa \lambda}\left[\frac{e^{-\kappa}}{\mathrm{x}_{0}}-\frac{\kappa^{1-\lambda \kappa}}{2 \mathrm{a}_{0}} \gamma(\lambda \kappa, \kappa \tau, \kappa)\right]
$$

Since $y=\mathrm{x}_{0}-1 / v$, one finally gets that the concentration profile of $\mathrm{X}-\mathrm{H}$ over $\tau=e^{-k_{a} t}$ can be written as:

$$
[\mathrm{X}-\mathrm{H}] \approx[\mathrm{X}-\mathrm{H}]_{0} \frac{e^{-\kappa \tau} \tau^{\kappa \lambda}}{e^{-\kappa}-(1-\lambda) \kappa^{1-\lambda \kappa} \gamma(\lambda \kappa, \kappa \tau, \kappa)}
$$

Together with the solutions derived from Eq. 1 and the ratio between Eq. 3 and Eq.4, the remaining equations of the ORAC kinetic system are:

$$
\begin{aligned}
& {[\mathrm{R}-\mathrm{N}=\mathrm{N}-\mathrm{R}]=[\mathrm{R}-\mathrm{N}=\mathrm{N}-\mathrm{R}]_{0} \tau} \\
& {[\mathrm{P}-\mathrm{X}] \approx[\mathrm{P}-\mathrm{X}]_{0}\left[\frac{e^{-\kappa \tau} \tau^{\kappa \lambda}}{e^{-\kappa}-(1-\lambda) \kappa^{1-\lambda \kappa} \gamma(\lambda \kappa, \kappa \tau, \kappa)}\right]^{k_{p} / k_{x}}} \\
& {\left[\mathrm{ROO}^{\bullet}\right] \approx 2[\mathrm{AAPH}]_{0}(1-\tau)-\left([\mathrm{X}-\mathrm{H}]_{0}-[\mathrm{X}-\mathrm{H}]\right)-\left([\mathrm{P}-\mathrm{H}]_{0}-[\mathrm{P}-\mathrm{H}]\right)}
\end{aligned}
$$


Since the minimal ORAC kinetic system only includes R.1-R.3, the model suggests that $\left[\mathrm{ROO}^{\circ}\right]$ increases after the consumption of $[\mathrm{X}-\mathrm{H}]+[\mathrm{P}-\mathrm{H}]$ in the reaction mixture. Experimental deviations from Eq.13 can be expected beyond this point at long reaction time if $\mathrm{ROO}^{\circ}$ accumulates in the reaction mixture and the self-reaction of $\mathrm{ROO}^{\circ}$ radicals and the formation of $\mathrm{RO}^{\circ}$ radicals (R.4-R.6) are not negligible.

\section{Comparison between the numerical and analytical solutions of the minimal ORAC} kinetic system

Once we have reached this point, we propose to examine the goodness of the approximation introduced in Eq.8. Figure 3 shows both the numerical and analytical solutions of the ODEs of the minimal ORAC kinetic system in two "limiting" situations that we can find when the reactivity of X-H is under study: one where the reactivity of $\mathrm{P}-\mathrm{H}$ is not very far form that of $\mathrm{X}-\mathrm{H}, k_{x} / k_{p}=5$, and another where the reactivity of the $\mathrm{X}-\mathrm{H}$ is between 1 and 2 orders of magnitude larger than that of $\mathrm{P}-\mathrm{H}, k_{x} / k_{p}=50$. The relative reactivity range we have chosen is in agreement with values for $k_{x} / k_{p}$ experimentally determined with different types of ORAC probes and methodologies. ${ }^{5,13,20,22}$ Absolute values of rate constants for the reaction of ROO radicals with representative $\mathrm{X}-\mathrm{H}$ have been reported using flash photolysis. ${ }^{21}$ Based on the introduced approximation, one must certainly expect that higher ratios $k_{x} / k_{p}$ should bring about better agreement between the numerical and analytical solutions of the ODE for the starting reactants $\mathrm{X}-\mathrm{H}$ and $\mathrm{P}-\mathrm{H}$, and the intermediate $\mathrm{ROO}{ }^{\circ}$ radical. If the changes in $[\mathrm{X}-\mathrm{H}]$ are observed while $[\mathrm{X}-\mathrm{H}]_{0} /[\mathrm{P}-\mathrm{H}]_{0}=10$, one can conclude that the fitting of both numerical and analytical solutions of their ODEs improve when 
$k_{x} / k_{p}=50$ and the changes in CV(RMSD)\% are below 5\% (Fig. 3A; Table 1).

However, the values of $\mathrm{CV}(\mathrm{RSMD}) \%$ for $\left[\mathrm{ROO}^{\circ}\right]$ are above $5 \%$ for $k_{x} / k_{p}=50$ and unacceptable for $k_{x} / k_{p}=5$ while $[\mathrm{X}-\mathrm{H}]_{0} /[\mathrm{P}-\mathrm{H}]_{0}=10$ (Fig. 3B; Table 1). When the fitting between the numerical and analytical solutions of the ODE for $[\mathrm{P}-\mathrm{H}]$ is inspected while $[\mathrm{X}-\mathrm{H}]_{0} /[\mathrm{P}-\mathrm{H}]_{0}=10$, the values of $\mathrm{CV}(\mathrm{RSMD}) \%$ do not show any great improvement from $k_{x} / k_{p}=5$ to $k_{x} / k_{p}=50$ and the mismatch in the decay region of [P-H] persists (Fig. 3C; Table 1).

The ratio between $[\mathrm{X}-\mathrm{H}]_{0} /[\mathrm{P}-\mathrm{H}]_{0}$ used in ORAC assay depends on the probe and the methodology. The concentrations of $[\mathrm{X}-\mathrm{H}]_{0}$ and $[\mathrm{P}-\mathrm{H}]_{0}$ are usually found in the same range if the ORAC method employs spectrophotometric or EPR probes, , $^{5,13,20,22}$ but certainly the $[\mathrm{X}-\mathrm{H}]_{0} /[\mathrm{P}-\mathrm{H}]_{0}$ ratio is much higher when the ORAC methods employs a fluorometric probe. ${ }^{1,3,13,14,19,20}[\mathrm{X}-\mathrm{H}]_{0} /[\mathrm{P}-\mathrm{H}]_{0}$ ratios beyond 100 can be even found in some of the previous studies. Table 2 shows several values for the $\mathrm{CV}(\mathrm{RSMD}) \%$ of $[\mathrm{P}-\mathrm{H}]$. In particular, the $\mathrm{CV}(\mathrm{RSMD}) \%$ decreases when the ratio $[\mathrm{X}-\mathrm{H}]_{0} /[\mathrm{P}-\mathrm{H}]_{0}$ increases, implying that the residual variance diminishes and the fitting between the numerical and analytical solutions of the ODE for $[\mathrm{P}-\mathrm{H}]$ over time becomes better. Figure 4 shows an example where the values of $\mathrm{CV}(\mathrm{RSMD}) \%$ for $[\mathrm{P}-\mathrm{H}],[\mathrm{P}-\mathrm{H}]$ and $\left[\mathrm{ROO}^{\circ}\right]$ are just below $2 \%$. In this case, the fitting of the numerical and analytical solutions of the ODEs for the three reactants $[\mathrm{X}-\mathrm{H}],[\mathrm{P}-\mathrm{H}]$ and $\left[\mathrm{ROO}^{\bullet}\right]$ improves under simulating conditions $\left(k_{x} / k_{p}=30\right.$ and $\left.[\mathrm{X}-\mathrm{H}]_{0} /[\mathrm{P}-\mathrm{H}]_{0}=40\right)$ that can be found experimentally. Both numerical and analytical solutions show how [ROO $\left.{ }^{\circ}\right]$ changes notably in the region where the consumption of $[\mathrm{X}-\mathrm{H}]$ is nearly complete, but 
the consumption of $[\mathrm{P}-\mathrm{H}]$ have just started (Figure 4). The termination reaction of tertiary ROO ${ }^{\circ}$ radicals is in the range of $10^{4} \mathrm{M}^{-1} \mathrm{~s}^{-1}$, two-four orders of magnitude lower than that for the reaction of $\mathrm{ROO}^{\circ}$ radicals with some representative $\mathrm{X}-\mathrm{H} \cdot{ }^{21,29}$ Such differences in the rate constants should not introduce significant modifications in the concentration profile of the starting reactants of the ORAC assay if in addition the initial concentration of the azo compound is kept low.

In conclusion, we show that the approximate analytical solution of the ODEs of the minimal ORAC kinetic system that we achieved in this study is very complex despite the apparent simplicity of the reaction scheme. The approximation implies that $k_{x}>k_{p},[\mathrm{X}-\mathrm{H}]_{0}>>[\mathrm{P}-\mathrm{H}]_{0}$ and the initial concentration of the azo compound must be low enough to neglect the $\mathrm{ROO}^{\circ}$ radical self-reaction and the $\mathrm{RO}^{\circ}$ formation. The applicability of the approximate analytical solution to normal ORAC assays is thus expected to have some limitations.

\section{Acknowledgements}

This study was funded by the Spanish Ministry of Economy and Competitiveness under grant number RTC-2014-3112-2 and Consejería de Educación, Junta de Castilla y León under grant number CSI231U14.

\section{Declaration of interest statement}

The authors hereby confirm they have no conflicts of interest.

\section{Bibliography}


1. Glazer, A. N. Meth Enzymol 1990, 186, 161-168.

2. Prior, R. L.; Wu, X.; Schaich, K. J Agric Food Chem 2005, 53, 4290-4302.

3. Gillespie, K. M.; Chae, J. M.; Ainsworth, E. A. Nat Protoc 2007, 2, 867-870.

4. Kohri, S.; Fujii, H.; Oowada, S.; Endoh, N.; Sueishi, Y.; Kusakabe, M.;

Shimmei, M.; Kotake, Y. Anal Biochem 2009, 386, 167-171.

5. Ramos, I. I.; Gregorio, B. J. R.; Barreiros, L.; Magalhaes, L. M.; Toth, I. V.;

Reis, S.; Lima, J. L. F. C.; Segundo, M. A. Talanta 2016, 150, 599-606.

6. Lopez-Alarcon, C.; Lissi, E. Free Radic Res 2005, 39, 729-736.

7. Schaich, K. M.; Tian, X.; Xie, J. J Funct Foods 2015, 14, 111-125.

8. Werber, J.; Wang, Y. J.; Milligan, M.; Li, X.; Ji, J. A. J Pharm Sci 2011, 100, $3307-3315$.

9. Krainev, A. G.; Bigelow, D. J. JCS Perkin (2) 1996, 747-754.

10. Dorta, E.; Fuentes-Lemus, E.; Aspee, A.; Atala, E.; Speisky, H.; Bridi, R.; Lissi, E.; Lopez-Alarcon, C. RSC Adv 2015, 5, 39899-39902.

11. Niki, E. Meth Enzymol 1990, 186, 100-108.

12. Huang, D.; Ou, B.; Prior, R. L. J Agric Food Chem 2005, 53, 1841-1856.

13. Pino, E.; Lissi, E. A. Helv Chim Acta 2001, 84, 3677-3685.

14. Naguib, Y. M. A. Anal Biochem 2000, 284, 93-98.

15. Chini, M. Rend Ist Lombardo (2) 1924, 57, 506-511.

16. Ibragimov, N. H. Lie group analysis of differential equations; CRC Press: Boca Raton, 1994.

17. Carinena, J. F.; de Lucas, J. Dissertationes Math 2011, 1-162.

18. Wolfram Research, I.; Wolfram Research, Inc.: Champaign, Illinois, 2015.

19. Ou, B. X.; Hampsch-Woodill, M.; Prior, R. L. J Agric Food Chem 2001, 49, 4619-4626. 
20. Lopez-Alarcon, C.; Lissi, E. Free Radic Res 2006, 40, 979-985.

21. Neta, P.; Huie, R. E.; Maruthamuthu, P.; Steenken, S. J Phys Chem 1989, 93, 7654-7659.

22. Kohri, S.; Fujii, H. J Clin Biochem Nutr 2013, 53, 134-138.

23. Slavova-Kazakova, A. K.; Angelova, S. E.; Veprintsev, T. L.; Denev, P.; Fabbri, D.; Dettori, M. A.; Kratchanova, M.; Naumov, V. V.; Trofimov, A. V.; Vasil'ev, R. F.; Delogu, G.; Kancheva, V. D. Beilstein J Org Chem 2015 2015, 11, 1398-1411.

24. Niki, E. Free Radic Biol Med 2010, 49, 503-515.

25. Cheb-Terrab, E. S.; Kolokolnikov, T. Eur J Appl Math 2003, 14, 231-246.

26. Edwards, M. P.; Anderssen, R. S. Commun Nonlinear Sci Numer Simul 2015, $22,1062-1067$.

27. Bruins, E. Recl Trav Chim Pays Bas 1940, 59, 738-740.

28. Chien, J. Y. J Am Chem Soc 1948 1948, 70, 2256-2261.

29. Ingold, K. U. Acc Chem Res 1969, 2, 1-9. 


\section{Figure Captions}

Figure 1. Numerical simulation of the concentration profile of $\mathrm{P}-\mathrm{H}$ over time using different values for $[\mathrm{X}-\mathrm{H}]_{0}$. The initial conditions for the starting and intermediate reactants were as follows: $[\mathrm{R}-\mathrm{N}=\mathrm{N}-\mathrm{R}]_{0}=80 \mu \mathrm{M},[\mathrm{P}-\mathrm{H}]_{0}=0.06 \mu \mathrm{M}$, $[\mathrm{X}-\mathrm{H}]_{0}=0-2 \mu \mathrm{M}$ and $\left[\mathrm{ROO}^{\bullet}\right]_{0}=0$. The values for $k_{a}, k_{p}$ and $k_{x}$ were $2.5 \times 10^{-6} \mathrm{~s}^{-1}, 10^{4} \mathrm{M}^{-1} \mathrm{~s}^{-1}$ and $10^{6} \mathrm{M}^{-1} \mathrm{~s}^{-1}$, respectively.

Figure 2. Numerical simulations of the concentration profiles of the starting and intermediate reactants of the ORAC assay over time. Plots of $[\mathrm{X}-\mathrm{H}]+[\mathrm{P}-\mathrm{H}]$ and the sum $\Sigma$ when the SSA is applied to $\left[\mathrm{ROO}^{\circ}\right]$ are also shown. The inset shows a zoom-in to better display the decay region of $[\mathrm{P}-\mathrm{H}]$. The initial conditions for the starting and intermediate reactants were as follows: $[\mathrm{R}-\mathrm{N}=\mathrm{N}-\mathrm{R}]_{0}=80 \mu \mathrm{M},[\mathrm{P}-\mathrm{H}]_{0}=0.06 \mu \mathrm{M}$, $[\mathrm{X}-\mathrm{H}]_{0}=1 \mu \mathrm{M}$ and $\left[\mathrm{ROO}^{\bullet}\right]_{0}=0$. The values for $k_{a}, k_{p}$ and $k_{x}$ were $\square 2.5 \times 10^{-6} \mathrm{~s}^{-1}$, $10^{4} \mathrm{M}^{-1} \mathrm{~s}^{-1}$ and $10^{6} \mathrm{M}^{-1} \mathrm{~s}^{-1}$, respectively. See the text for further details.

Figure 3. Comparison between the numerical and analytical solutions of the ODEs of the minimal ORAC kinetic system after applying the approximation $k_{x}>k_{p}$. Panels A-C respectively compares the numerical solution (NS) and the analytical solutions (AS) of the ODEs for $[\mathrm{X}-\mathrm{H}],\left[\mathrm{ROO}^{\circ}\right]$ and $[\mathrm{P}-\mathrm{H}]$ using two different ratios for $k_{x} / k_{p}$. Panel A contains a zoom-in to better observe the differences between the NS and AS in the region between $t=1.1-1.5 \mathrm{~h}$ and $[\mathrm{X}-\mathrm{H}]=0-0.25 \mu \mathrm{M}$. The initial conditions for the starting and intermediate reactants were as follows: $[\mathrm{R}-\mathrm{N}=\mathrm{N}-\mathrm{R}]_{0}=80 \mu \mathrm{M}$, 
$[\mathrm{P}-\mathrm{H}]_{0}=0.2 \mu \mathrm{M},[\mathrm{X}-\mathrm{H}]_{0}=2 \mu \mathrm{M}$ and $\left[\mathrm{ROO}^{\bullet}\right]_{0}=0$. The values for $k_{a}$ and $k_{p}$ were

$\square 2.5 \times 10^{-6} \mathrm{~s}^{-1}$ and $10^{4} \times \mathrm{M}^{-1} \mathrm{~s}^{-1}$ respectively, and $k_{x}$ was $5 \times 10^{4} \mathrm{M}^{-1} \mathrm{~s}^{-1}$ or $5 \times 10^{5} \mathrm{M}^{-1} \mathrm{~s}^{-1}$.

Figure 4. Representative numerical (NS) and analytical (AS) solutions for the ODEs of the minimal ORAC kinetic system after applying the approximation $k_{x}>>k_{p}$ and when the values of $\mathrm{CV}(\mathrm{RMSD}) \%$ for $[\mathrm{X}-\mathrm{H}],\left[\mathrm{ROO}^{\circ}\right]$ and $[\mathrm{P}-\mathrm{H}]$ are below $2 \%$. The initial conditions for the starting and intermediate reactants were as follows:

$[\mathrm{R}-\mathrm{N}=\mathrm{N}-\mathrm{R}]_{0}=80 \mu \mathrm{M},[\mathrm{P}-\mathrm{H}]_{0}=0.05 \mu \mathrm{M},[\mathrm{X}-\mathrm{H}]_{0}=2 \mu \mathrm{M}$ and $\left[\mathrm{ROO}^{\bullet}\right]_{0}=0$. The values for $k_{a}, k_{p}$ and $k_{x}$ were $\square 2.5 \times 10^{-6} \mathrm{~s}^{-1}, 10^{4} \times \mathrm{M}^{-1} \mathrm{~s}^{-1}$ and $3 \times 10^{5} \mathrm{M}^{-1} \mathrm{~s}^{-1}$ respectively.

Figure S1. Numerical simulation of the concentration profile of $\mathrm{P}-\mathrm{H}$ over time using different values for the ratio between $k_{p}$ and $k_{x}$. The initial conditions for the starting and intermediate reactants were as follows: $[\mathrm{R}-\mathrm{N}=\mathrm{N}-\mathrm{R}]_{0}=80 \mu \mathrm{M},[\mathrm{P}-\mathrm{H}]_{0}=0.06 \mu \mathrm{M}$, $[\mathrm{X}-\mathrm{H}]_{0}=1 \mu \mathrm{M}$ and $\left[\mathrm{ROO}^{\bullet}\right]_{0}=0$. The values for $k_{a}$ and $k_{p}$ were $\square 2.5 \times 10^{-6} \mathrm{~s}^{-1}$, $10^{4} \mathrm{M}^{-1} \mathrm{~s}^{-1}$ and $k_{x}$ ranged from 0 to $10^{6} \mathrm{M}^{-1} \mathrm{~s}^{-1}$, respectively.

Figure S2. Numerical simulation of the concentration profile (panels A and B) and consumption rate (panels $\mathrm{C}$ and $\mathrm{D}$ ) of $\mathrm{P}-\mathrm{H}$ over time using different ratios between $[\mathrm{X}-\mathrm{H}]_{0}$ and $[\mathrm{P}-\mathrm{H}]_{0}$, and between $k_{p}$ and $k_{x}$. The initial conditions for the starting and intermediate reactants were as follows: $[\mathrm{R}-\mathrm{N}=\mathrm{N}-\mathrm{R}]_{0}=80 \mu \mathrm{M},[\mathrm{P}-\mathrm{H}]_{0}=0.2-1 \mu \mathrm{M}$, $[\mathrm{X}-\mathrm{H}]_{0}=1 \mu \mathrm{M}$ and $\left[\mathrm{ROO}^{\bullet}\right]_{0}=0$. The values for $k_{a}$ and $k_{p}$ were $\square 2.5 \times 10^{-6} \mathrm{~s}^{-1}$, 
$10^{4} \mathrm{M}^{-1} \mathrm{~s}^{-1}$ and $k_{x}$ was $10^{5} \mathrm{M}^{-1} \mathrm{~s}^{-1}$ (panels A and C) or $5 \times 10^{5} \mathrm{M}^{-1} \mathrm{~s}^{-1}$ (panels B and D), respectively.

1

2

3

4

5

6

7

8

9

10

11

12

13

14

15

16

17

18

19

20

21

22

23

24

25

26

27

28

29

30

31

32

33

34

35

36

37

38

39

40

41

42

43

44

45

46

47

48

49

50

51

52

53

54

55

56

57

58

59

60

John Wiley \& Sons, Inc. 
Table 1. Coefficient of variation (\%) of the RMSD of the difference between the numerical and analytical solutions of the profile of $[\mathrm{P}-\mathrm{H}],[\mathrm{X}-\mathrm{H}]$ and $\left[\mathrm{ROO}^{\bullet}\right]$ over time using different ratios for $k_{x} / k_{p}$ and a constant ratio of $[\mathrm{X}-\mathrm{H}]_{0} /[\mathrm{P}-\mathrm{H}]_{0}=10{ }^{*}$

\begin{tabular}{cccc}
\hline$k_{x} / k_{p}$ & {$[\mathrm{X}-\mathrm{H}]$} & {$\left[\mathrm{ROO}^{\bullet}\right]$} & {$[\mathrm{P}-\mathrm{H}]$} \\
5 & 4,41 & 24,22 & 8,57 \\
10 & 2,56 & 14,19 & 7,84 \\
15 & 1,81 & 10,67 & 7,34 \\
20 & 1,41 & 8,94 & 6,99 \\
25 & 1,15 & 7,94 & 6,75 \\
30 & 0,98 & 7,30 & 6,56 \\
35 & 0,85 & 6,86 & 6,42 \\
40 & 0,75 & 6,54 & 6,31 \\
45 & 0,67 & 6,31 & 6,22 \\
50 & 0,61 & 6,12 & 6,14 \\
\hline
\end{tabular}

"The initial conditions for the starting and intermediate reactants were as follows:

$[\mathrm{R}-\mathrm{N}=\mathrm{N}-\mathrm{R}]_{0}=80 \mu \mathrm{M},[\mathrm{P}-\mathrm{H}]_{0}=0.2 \mu \mathrm{M},[\mathrm{X}-\mathrm{H}]_{0}=2 \mu \mathrm{M}$ and $\left[\mathrm{ROO}^{\circ}\right]_{0}=0$. The values for $k_{a}$ and $k_{p}$ were $\square 2.5 \times 10^{-6} \mathrm{~s}^{-1}$ and $10^{4} \times \mathrm{M}^{-1} \mathrm{~s}^{-1}$ respectively, and $k_{x}$ ranged from $5 \times 10^{4} \mathrm{M}^{-1} \mathrm{~s}^{-1}$ to $5 \times 10^{5} \mathrm{M}^{-1} \mathrm{~s}^{-1}$. 
Table 2. Coefficient of variation (\%) of the RMSD of the difference between the numerical and analytical solutions of the profile of $[\mathrm{P}-\mathrm{H}]$ over time using different ratios for $k_{x} / k_{p}$ and $[\mathrm{X}-\mathrm{H}]_{0} /[\mathrm{P}-\mathrm{H}]_{0}{ }^{*}$

\begin{tabular}{c|ccccc}
\hline$k_{x} / k_{p}$ & \multicolumn{5}{c}{$[\mathrm{X}-\mathrm{H}]_{0} /[\mathrm{P}-\mathrm{H}]_{0}$} \\
& 10 & 20 & 30 & 40 & 50 \\
\hline 10 & 7,84 & 3,95 & 2,64 & 1,98 & 1,59 \\
20 & 6,99 & 3,50 & 2,33 & 1,75 & 1,40 \\
30 & 6,56 & 3,27 & 2,17 & 1,63 & 1,30 \\
40 & 6,31 & 3,13 & 2,08 & 1,55 & 1,24 \\
50 & 6,14 & 3,03 & 2,01 & 1,51 & 1,20 \\
\hline
\end{tabular}

The initial conditions for the starting and intermediate reactants were as follows: $[\mathrm{R}-\mathrm{N}=\mathrm{N}-\mathrm{R}]_{0}=80 \mu \mathrm{M},[\mathrm{P}-\mathrm{H}]_{0}=0.04-0.2 \mu \mathrm{M},[\mathrm{X}-\mathrm{H}]_{0}=2 \mu \mathrm{M}$ and $\left[\mathrm{ROO}^{\bullet}\right]_{0}=0$. The values for $k_{a}$ and $k_{p}$ were $\square 2.5 \times 10^{-6} \mathrm{~s}^{-1}$ and $10^{4} \times \mathrm{M}^{-1} \mathrm{~s}^{-1}$ respectively, and $k_{x}$ ranged from $10^{5} \mathrm{M}^{-1} \mathrm{~s}^{-1}$ to $5 \times 10^{5} \mathrm{M}^{-1} \mathrm{~s}^{-1}$. 
2

3

4

5

6

7

8

9

10

11

12

13

14

15

16

17

18

19

20

21

22

23

24

25

26

27

28

29

30

31

32

33

34

35

36

37

38

39

40

41

42

43

44

45

46

47

48

49

50

51

52

53

54

55

56

57

58

59

60

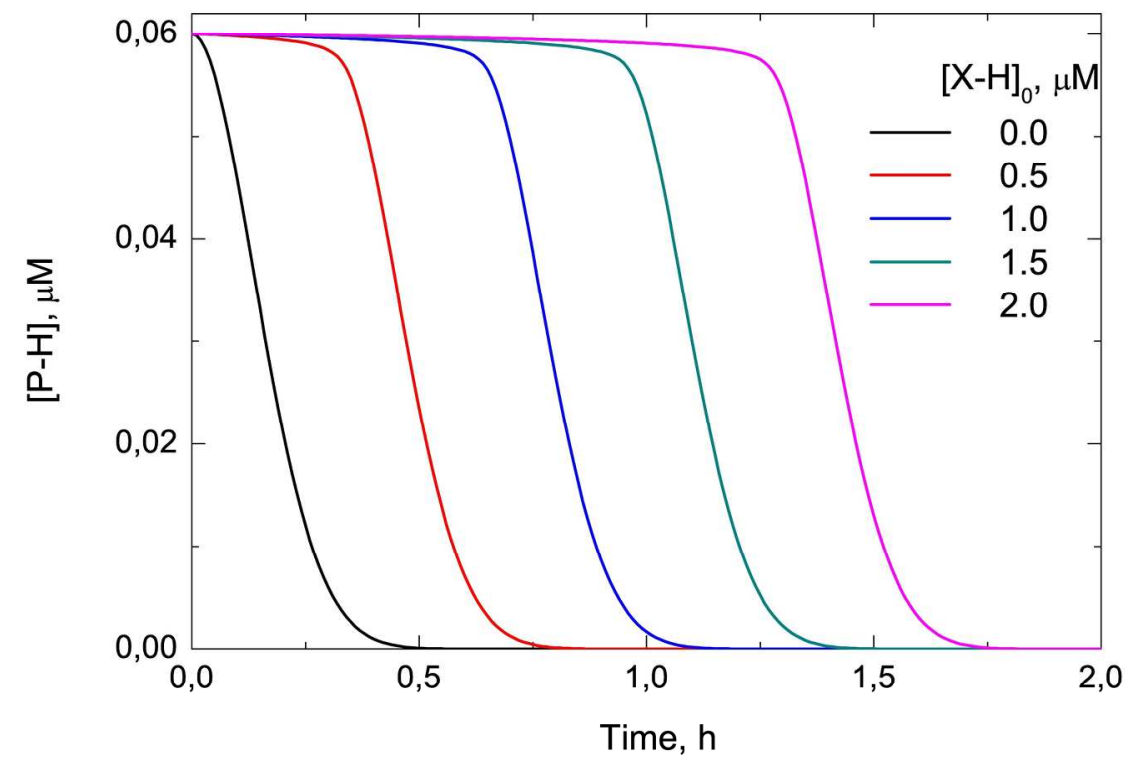

Figure 1. Numerical simulation of the concentration profile of $\mathrm{P}-\mathrm{H}$ over time using different values for $[\mathrm{X}-\mathrm{H}]_{0}$. The initial conditions for the starting and intermediate reactants were as follows: $[R-N=N-R]_{0}=80 \mu M$, $[P-$ $\mathrm{H}]_{0}=0.06 \mu \mathrm{M},[\mathrm{X}-\mathrm{H}]_{0}=0-2 \mu \mathrm{M}$ and $[\mathrm{ROO} \cdot]_{0}=0$. The values for $k_{\mathrm{a}}, k_{\mathrm{x}}$ and $k_{\mathrm{p}}$ were $2.5 \times 10^{-6} \mathrm{~s}^{-1}, 10^{4} \mathrm{M}^{-1} \mathrm{~s}^{-1}$ and $10^{6} \mathrm{M}^{-1} \mathrm{~s}^{-1}$, respectively.

$201 \times 140 \mathrm{~mm}(300 \times 300 \mathrm{DPI})$

John Wiley \& Sons, Inc. 
Figure 2. Numerical simulations of the concentration profiles of the starting and intermediate reactants of the ORAC assay over time. Plots of $[\mathrm{X}-\mathrm{H}]+[\mathrm{P}-\mathrm{H}]$ and the sum $\Sigma$ when the SSA is applied to [ROO·] are also shown. The inset shows a zoom-in to better display the decay region of $[\mathrm{P}-\mathrm{H}]$. The initial conditions for the starting and intermediate reactants were as follows: $[R-N=N-R]_{0}=80 \mu M,[P-H]_{0}=0.06 \mu M,[X-H]_{0}=1 \mu M$ and $[\mathrm{ROO} \cdot]_{0}=0$. The values for $k_{\mathrm{a}}, k_{\mathrm{x}}$ and $k_{\mathrm{p}}$ were $2.5 \times 10^{-6} \mathrm{~s}^{-1}, 10^{4} \mathrm{M}^{-1} \mathrm{~s}^{-1}$ and $10^{6} \mathrm{M}^{-1} \mathrm{~s}^{-1}$, respectively. See the text for further details.

$201 \times 140 \mathrm{~mm}(300 \times 300$ DPI $)$ 
Figure 3. Comparison between the numerical and analytical solutions of the ODEs of the minimal ORAC kinetic system after applying the approximation $k_{\mathrm{x}}>>k_{\mathrm{p}}$. Panels $\mathrm{A}-\mathrm{C}$ respectively compares the numerical solution (NS) and the analytical solutions (AS) of the ODEs for $[\mathrm{X}-\mathrm{H}],[\mathrm{ROO} \cdot]$ and $[\mathrm{P}-\mathrm{H}]$ using two different ratios for $k_{\mathrm{x}} / k_{\mathrm{p}}$. Panel A contains a zoom-in to better observe the differences between the NS and AS in the region between $t=1.1-1.5 \mathrm{~h}$ and $[\mathrm{X}-\mathrm{H}]=0-0.25 \mu \mathrm{M}$. The initial conditions for the starting and intermediate reactants were as follows: $[\mathrm{R}-\mathrm{N}=\mathrm{N}-\mathrm{R}]_{0}=80 \mu \mathrm{M},[\mathrm{P}-\mathrm{H}]_{0}=0.2 \mu \mathrm{M},[\mathrm{X}-\mathrm{H}]_{0}=2 \mu \mathrm{M}$ and $[\mathrm{ROO} \cdot]_{0}=0$. The values for $k_{\mathrm{a}}$ and $k_{\mathrm{p}}$ were $2.5 \times 10^{-6} \mathrm{~s}^{-1}$ and $10^{4} \mathrm{M}^{-1} \mathrm{~s}^{-1}$, respectively, and $k_{\mathrm{x}}$ was $5 \times 10^{4} \mathrm{M}^{-1} \mathrm{~s}^{-1}$ or $5 \times 10^{5} \mathrm{M}^{-1} \mathrm{~s}^{-1}$.

$$
410 \times 588 \mathrm{~mm} \text { ( } 300 \times 300 \text { DPI) }
$$




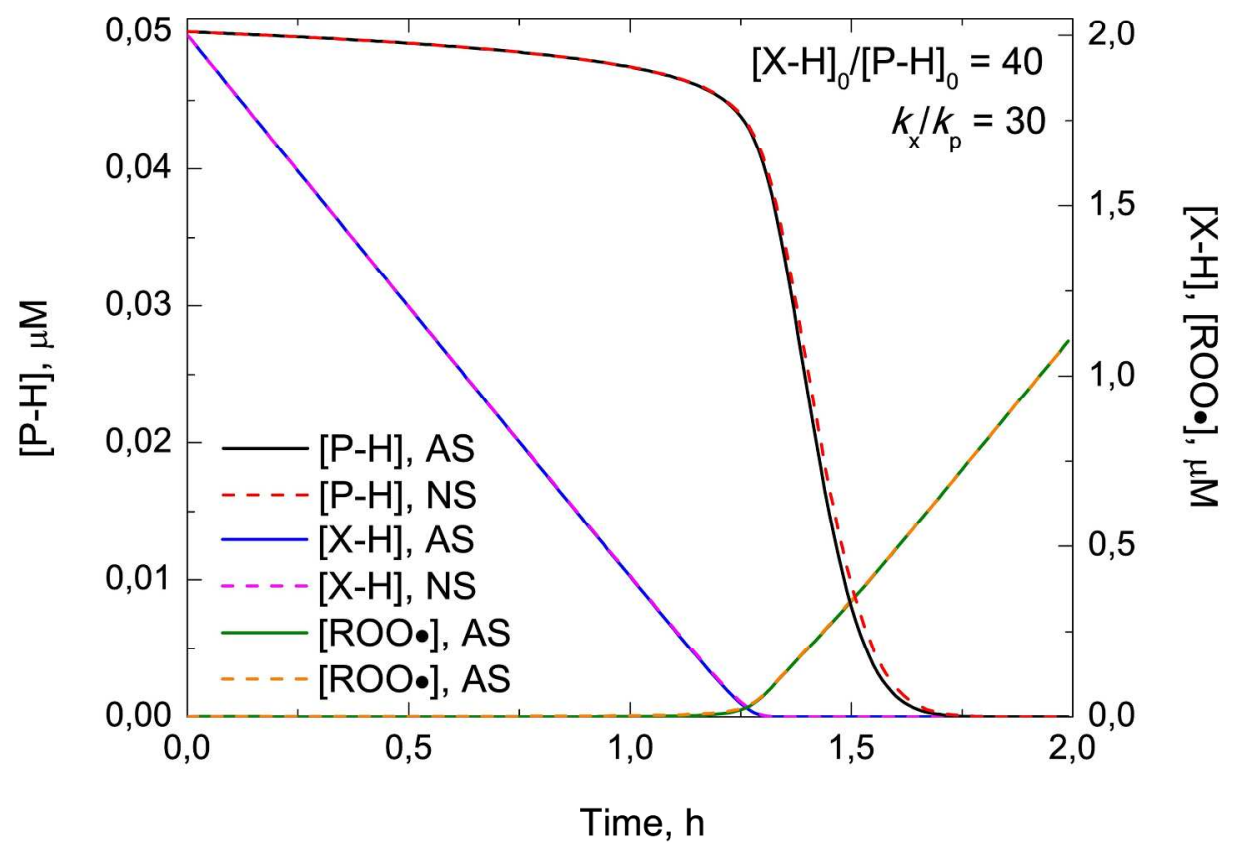

Figure 4. Representative numerical (NS) and analytical (AS) solutions for the ODEs of the minimal ORAC kinetic system after applying the approximation $k_{\mathrm{x}}>k_{\mathrm{p}}$ and when the values of CV(RMSD)\% for [X-H], [ROO.] and [P-H] are below 2\%. The initial conditions for the starting and intermediate reactants were as follows: $[\mathrm{R}-\mathrm{N}=\mathrm{N}-\mathrm{R}]_{0}=80 \mu \mathrm{M},[\mathrm{P}-\mathrm{H}]_{0}=0.05 \mu \mathrm{M},[\mathrm{X}-\mathrm{H}]_{0}=2 \mu \mathrm{M}$ and $[\mathrm{ROO} \cdot]_{0}=0$. The values for $k_{\mathrm{a}}, k_{\mathrm{p}}$ and $k_{\mathrm{x}}$ were $2.5 \times 10^{-6} \mathrm{~s}^{-1}, 10^{4} \mathrm{M}^{-1} \mathrm{~s}^{-1}$ and $3 \times 10^{5} \mathrm{M}^{-1} \mathrm{~s}^{-1}$.

$220 \times 168 \mathrm{~mm}(300 \times 300 \mathrm{DPI})$

John Wiley \& Sons, Inc. 


\section{Online Resource 1:}

\section{NUMERICAL SOLUTION OF THE ODES OF THE MINIMAL ORAC KINETIC SYSTEM}

The ORAC Assay: Mathematical Analysis of the Rate Equations and Some Practical Considerations

Juan B. Arellano, Elena Mellado-Ortega, and K. Razi Naqvi

The numerical solution of the ordinary differential equations (ODEs) of the minimal ORAC kinetic system (R1-R3 reaction scheme) is given below using the "ParametricNDSolve" command of the computer algebra system Wolfram Mathematica 10.3.

The parametricNDSolve command $\left[\left\{\mathrm{f}^{\prime}, \mathrm{f} 2{ }^{\prime}, \ldots\right\},\{\mathrm{f} 1, \mathrm{f} 2, \ldots\},\{\mathrm{t}, \mathrm{tmin}, \mathrm{t} \max \},\{\mathrm{f} 1 \mathrm{o}, \mathrm{f} 2 \mathrm{o}, \ldots, \mathrm{k} 1, \mathrm{k} 2, \ldots\}\right]$ finds numerical solutions to the ordinary differential equations $\mathrm{f}^{\prime}{ }^{\prime}, \mathrm{f} 2$ ', $\ldots$ for the functions $\mathrm{f} 1, \mathrm{f} 2, \ldots$ with the independent variable $t$ in the range tmin to tmax with the parameters $f 10, f 2 o, \ldots, k 1, k 2, \ldots$. .The input parameters in this study are the initial concentrations of the reactants and the reaction rate constants.

For the numerical solution of the ODEs of the minimal ORAC assay system, the "ParametricNDSolve" command can be written as follows:

(NOTE: The commands run when shift plus enter are pressed together and the cursor is at the end of the $\ln [$ ] of the selected command.)

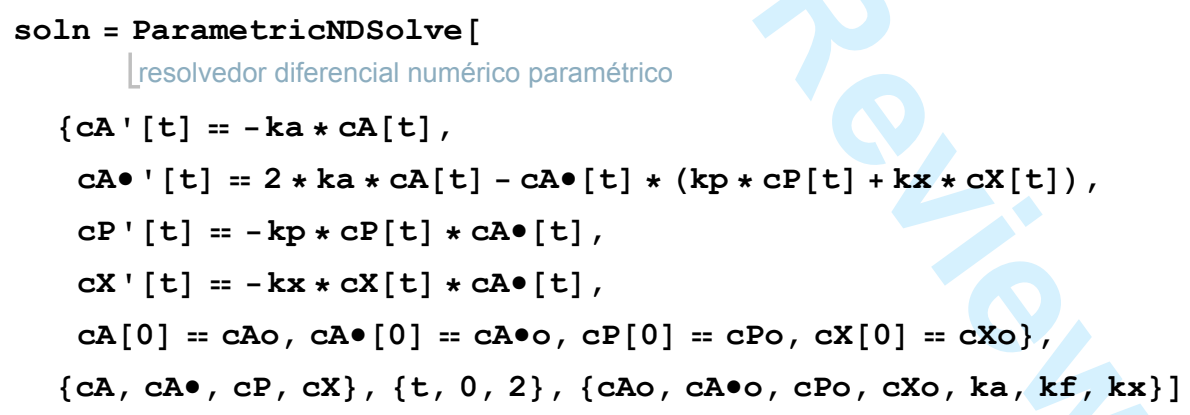


The output can now be evaluated. Similarly, the user can plot the output or retrieve the output as a list of data points. The Plot and Table commands allow the user to plot several functions or retrieve several lists of data points if the parameters are also allowed to change in a range of values together with the independent variable. The data points per list will depend on the increments selected for the independent variable. When one parameter is expected to have a constant value in the analysis, the use can fix a value or make the minimal and maximal values equal .

The units for the concentration of azo compound $(\mathrm{CA})$, peroxyl radical $(\mathrm{CA} \bullet)$, probe $(\mathrm{cP})$ and antioxidant (cX) are given in $\mu \mathrm{M}$. The units for ka are given in $\mathrm{h}-1$ and for $\mathrm{kp}$ and $\mathrm{kx}$ are given in $\mu \mathrm{M}-1 \cdot \mathrm{h}-1$. The letter "o" stands for initial conditions $(\mathrm{t}=0)$. The range of values for the initial concentration of reactants and the reaction rate constants are in accordance with those values reported in the papers included in the Material and Methods section of this study.

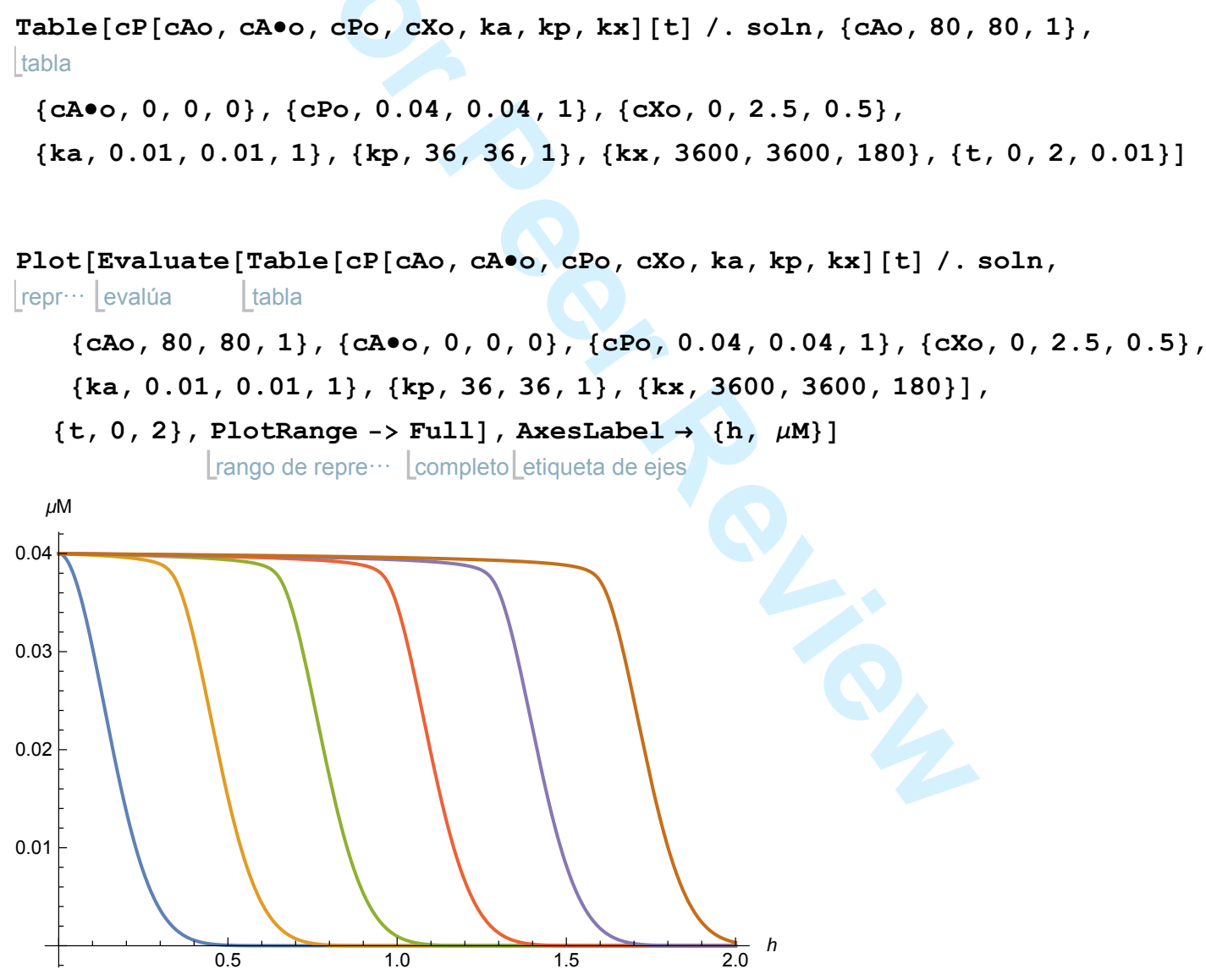

The changes in the concentration profile of several reactants over time can be inspected and plotted simultaneously in the same figure. Likewise, mathematical operations can be applied to the functions of the reactant concentrations over time. The results can be compared with other functions that simulate, for example, the steady state approximation (SSA) for CA •. 


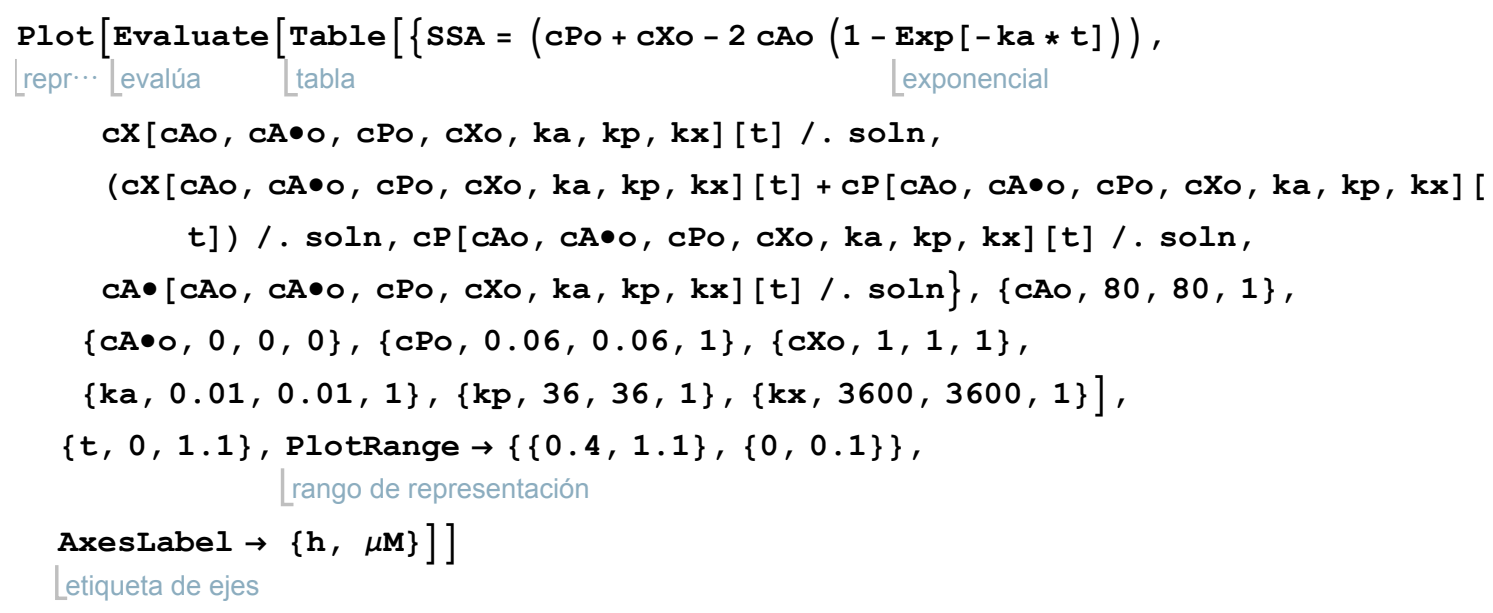




\section{Online Resource 2:}

\section{MATHEMATICAL SOLUTION OF THE ODES OF THE MINIMAL ORAC KINETIC SYSTEM}

The ORAC Assay: Mathematical Analysis of the Rate Equations and Some Practical Considerations

Juan B. Arellano, Elena Mellado-Ortega, and K. Razi Naqvi

After the approximation $\mathrm{kx}>>\mathrm{kp}$ introduced in the Chini equation (Eq. 6), a analytical solution for the ODEs of the minimal ORAC kinetic system is reached. The functions corresponding with changes in the concentration of the probe (cP), the antioxidant (cX) and the peroxyl radical $(\mathrm{cA} \bullet)$ over time are now presented. For each reactant the Plot and Table commands are displayed to visualize the results and to carry the analysis of $\mathrm{CV}(\mathrm{RMSD}) \%$ when the numerical and analytical solutions are compared.

The units for the concentration of the azo compound $(\mathrm{cA})$, the peroxyl radical $(\mathrm{cA} \bullet)$, the probe $(\mathrm{cP})$ and the antioxidant (cX) are given in $\mu \mathrm{M}$. The units for ka are given in $\mathrm{h}-1$ and for $\mathrm{kp}$ and $\mathrm{kx}$ are given in $\mu \mathrm{M}-1 \cdot \mathrm{h}-1$. The letter "o" stands for initial conditions $(\mathrm{t}=0)$. The input parameters in this study are the initial concentrations of the reactants and the reaction rate constants. The range of values for the initial concentration of reactants and the reaction rate constants are in accordance with those values reported in the papers included in the Material and Methods section of this study.

(NOTE: The commands run when shift plus enter are pressed together and the cursor is at the end of the $\ln [$ ] of the selected command.)

\section{Changes in $c P$ over time}

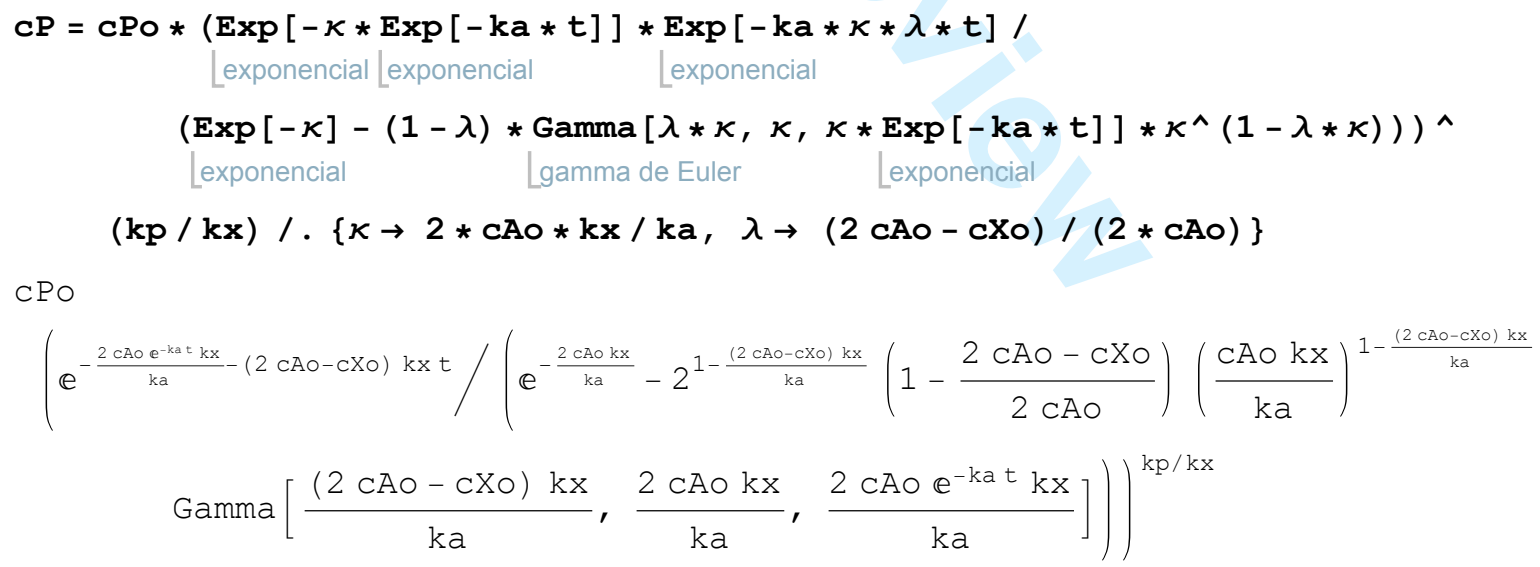


2 | Online resource 2.nb

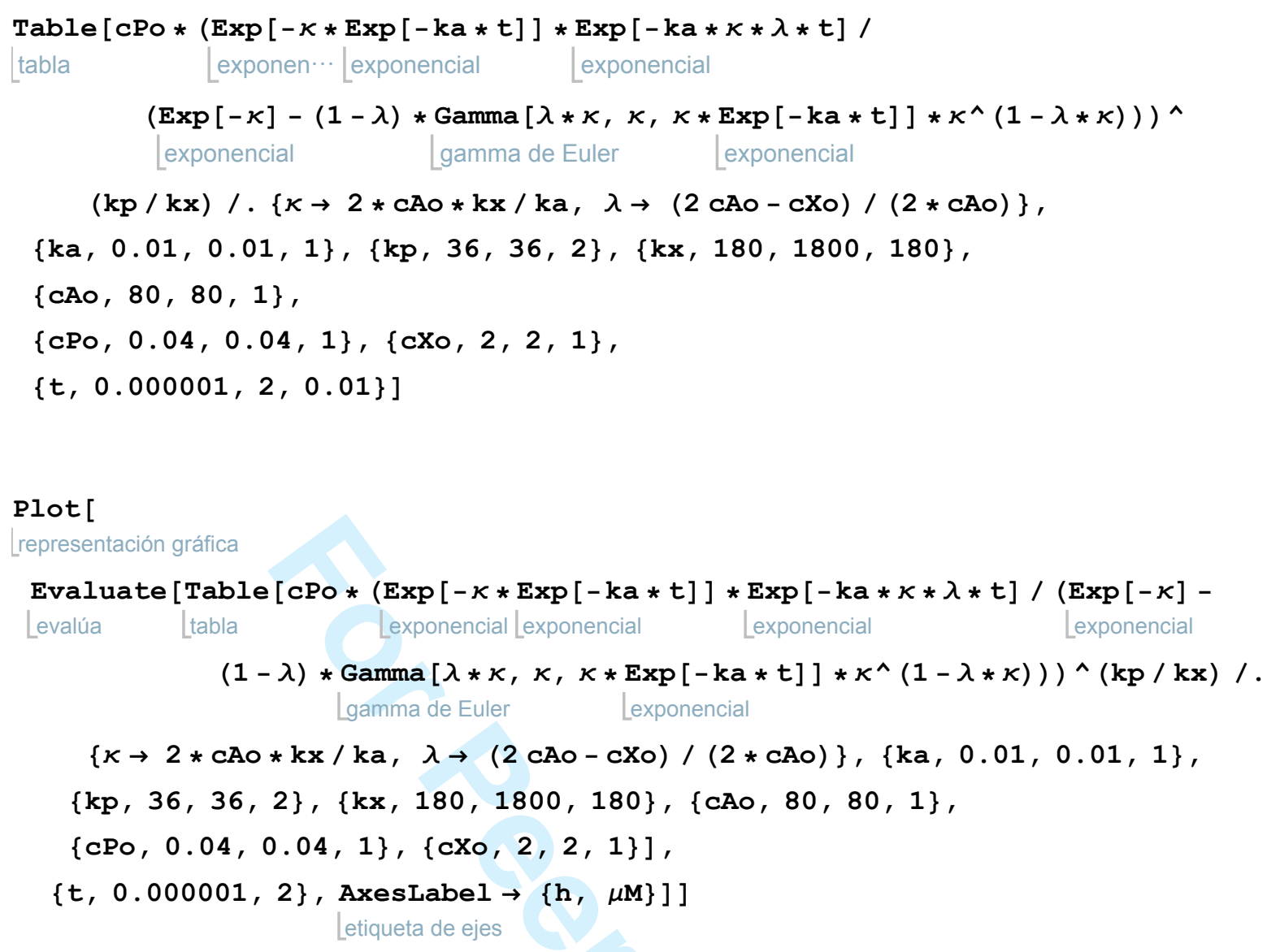

2. Changes in cX over time

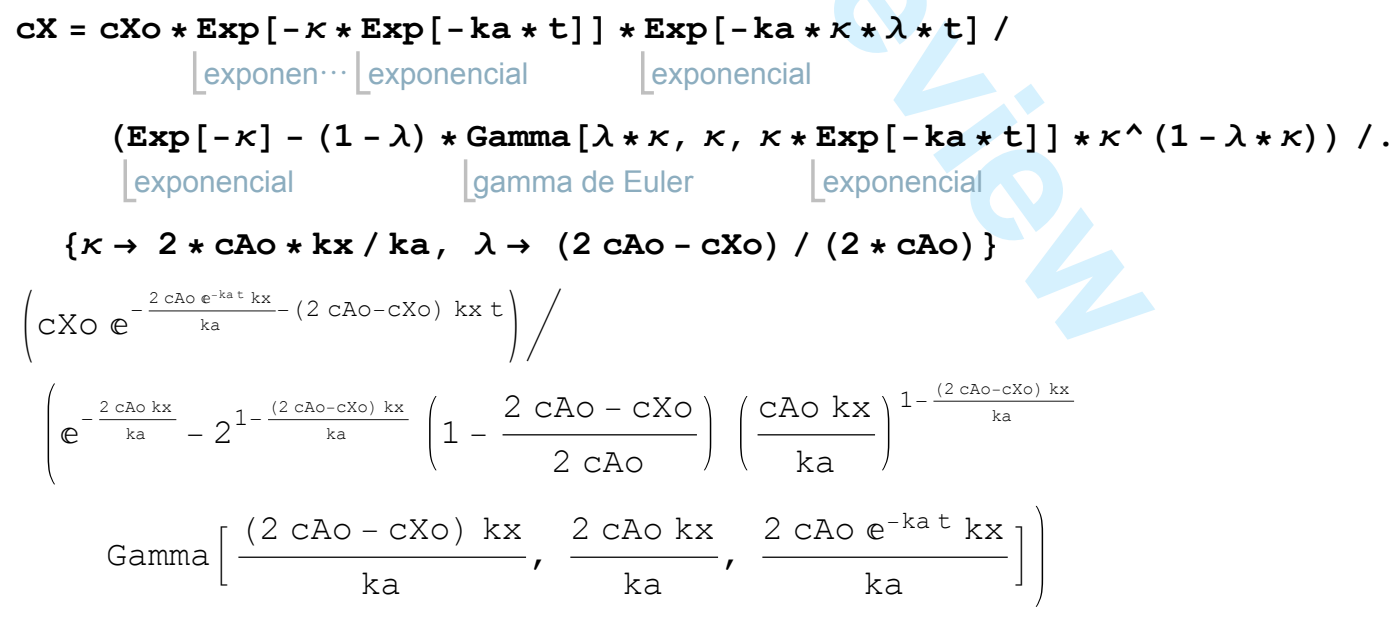




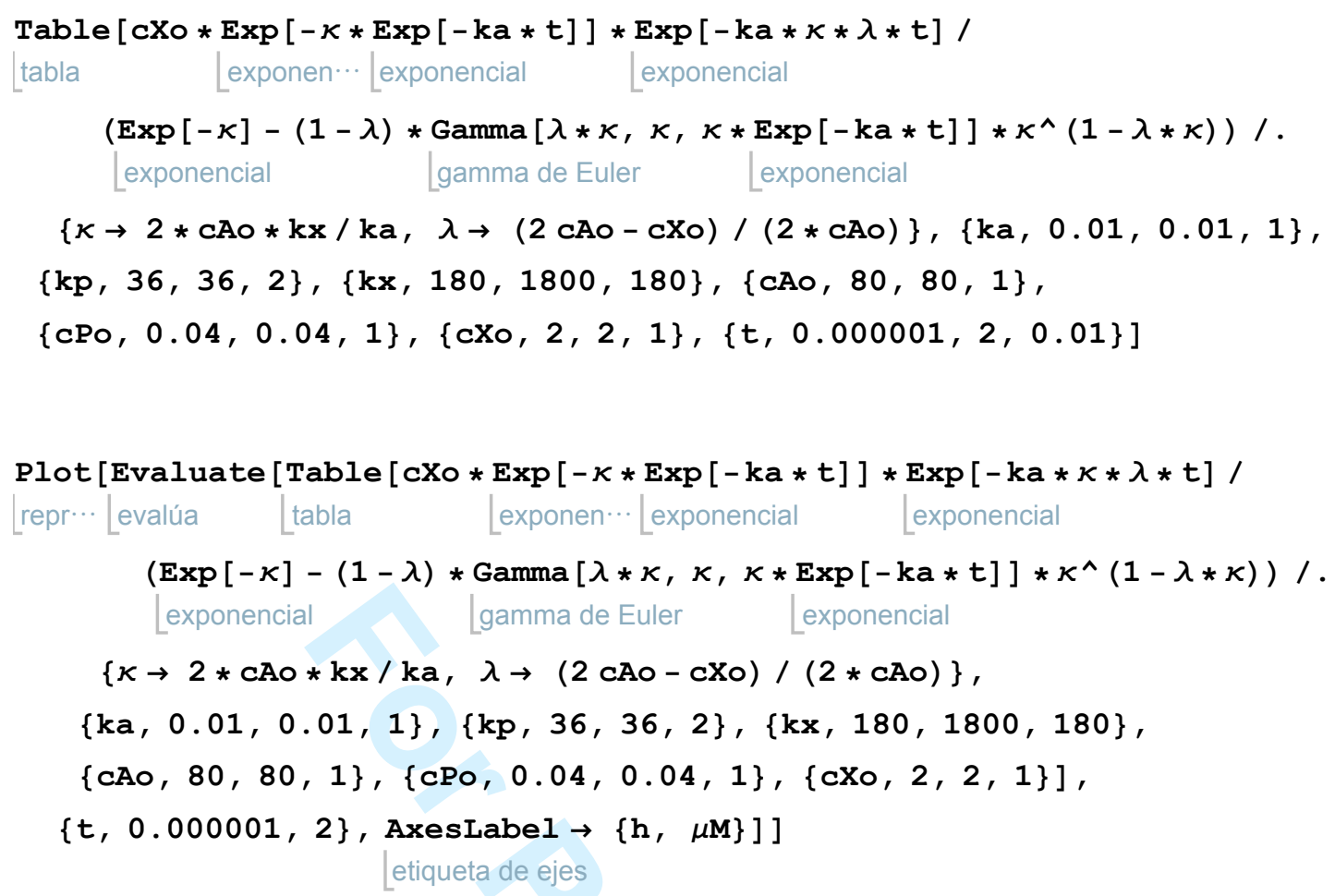

3. Changes in $C A \bullet$ over time 
4 | Online resource 2.nb

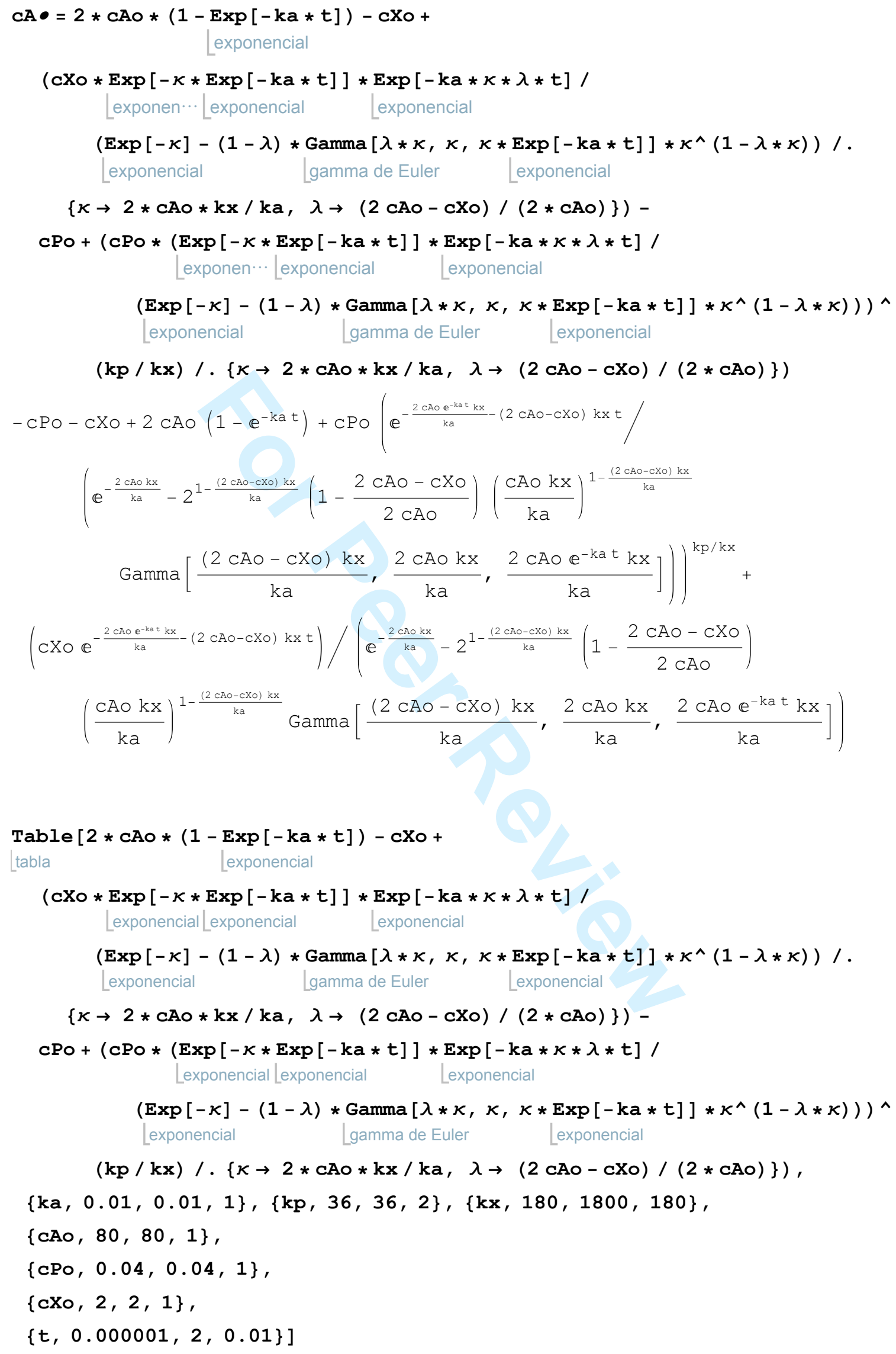




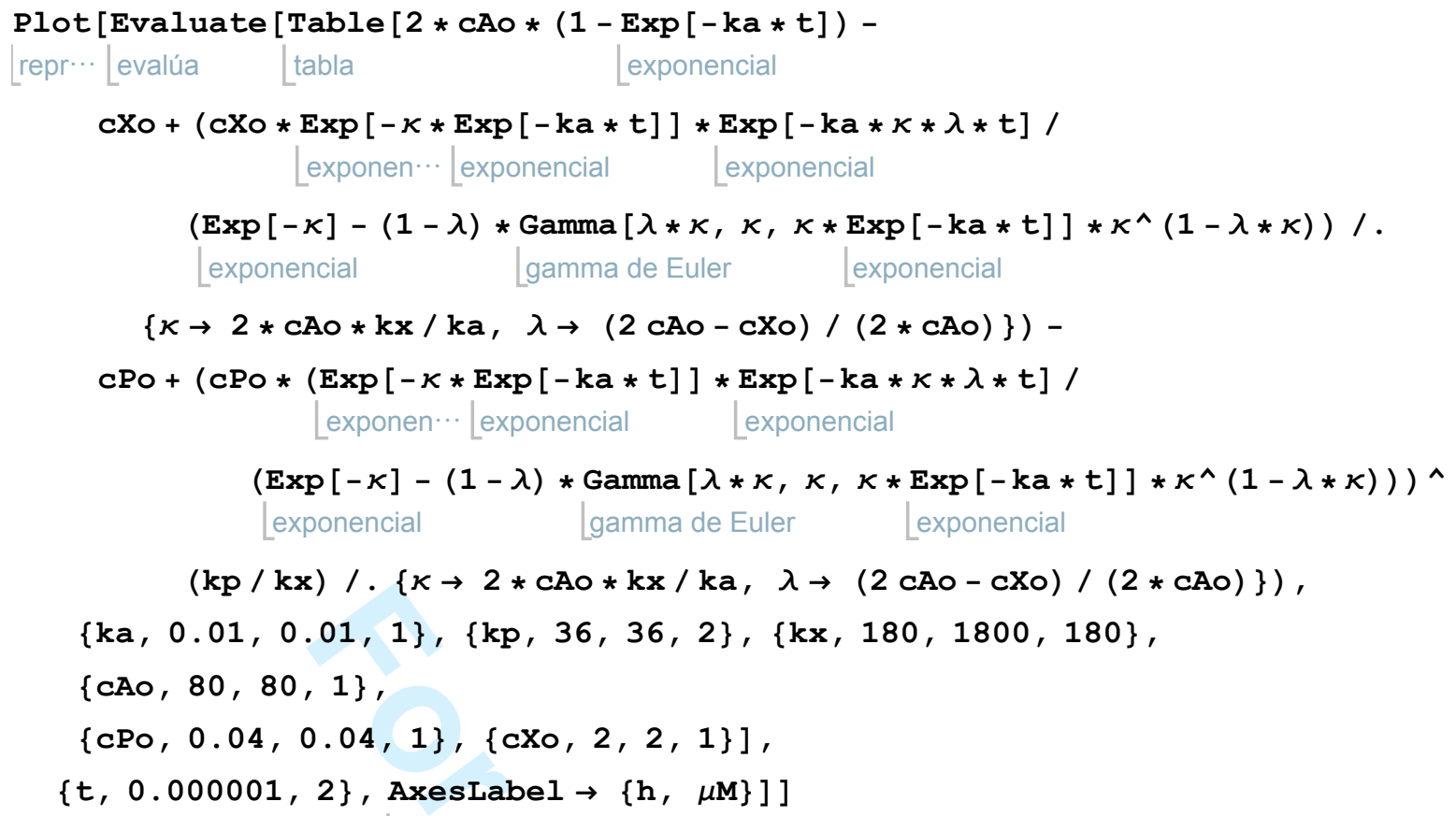




\section{Online Resource 3:}

\section{APPLICATION OF THE STEADY STATE APPROXIMATION TO THE MINIMUM ORAC KINETIC SYSTEM}

The ORAC Assay: Mathematical Analysis of the Rate Equations and Some Practical Considerations

Juan B. Arellano, Elena Mellado-Ortega, and K. Razi Naqvi

The first-order ODEs of the minimal ORAC kinetic system can be represented as follows:

$$
\begin{aligned}
& \frac{d[\mathrm{R}-\mathrm{N}=\mathrm{N}-\mathrm{R}]}{d t}=-k_{a}[\mathrm{R}-\mathrm{N}=\mathrm{N}-\mathrm{R}] \\
& \frac{d\left[\mathrm{ROO}^{\bullet}\right]}{d t}=2 k_{a}[\mathrm{R}-\mathrm{N}=\mathrm{N}-\mathrm{R}]-\left(k_{x}[\mathrm{X}-\mathrm{H}]+k_{p}[\mathrm{P}-\mathrm{H}]\right)\left[\mathrm{ROO}^{\bullet}\right] \\
& \frac{d[\mathrm{P}-\mathrm{H}]}{d t}=-k_{p}\left[\mathrm{ROO}^{\bullet}\right][\mathrm{P}-\mathrm{H}] \\
& \frac{d[\mathrm{X}-\mathrm{H}]}{d t}=-k_{x}\left[\mathrm{ROO}^{\bullet}\right][\mathrm{X}-\mathrm{H}]
\end{aligned}
$$

At $t=0$, the concentration of the starting and intermediate reactants are taken to be $[\mathrm{R}-\mathrm{N}=\mathrm{N}-\mathrm{R}]=[\mathrm{R}-\mathrm{N}=\mathrm{N}-\mathrm{R}]_{0},\left[\mathrm{ROO}{ }^{\bullet}\right]=0,[\mathrm{X}-\mathrm{H}]=[\mathrm{X}-\mathrm{H}]_{0}$ and $[\mathrm{P}-\mathrm{H}]=[\mathrm{P}-\mathrm{H}]_{0}$.

Equation 2 can also be written as:

$$
\left[\mathrm{ROO}^{\bullet}\right]+\tau_{s}(t) \frac{d\left[\mathrm{ROO}^{\bullet}\right]}{d t}=\frac{2 \tau_{s}(t)}{\tau_{a}}[\mathrm{R}-\mathrm{N}=\mathrm{N}-\mathrm{R}]
$$

where $\tau_{a}=\left(k_{a}\right)^{-1}$ and $\tau_{s}(t)=\left(k_{p}[\mathrm{P}-\mathrm{H}]+k_{x}[\mathrm{X}-\mathrm{H}]\right)^{-1}$ 
We see from Eq. 5 and $\left[\mathrm{ROO}^{\circ}\right]_{0}=0$ that

$$
\left.\frac{d\left[\mathrm{ROO}^{\bullet}\right]}{d t}\right]_{t=0}=\frac{2}{\tau_{a}}[\mathrm{R}-\mathrm{N}=\mathrm{N}-\mathrm{R}]_{0}>0
$$

As time proceeds, $[\mathrm{R}-\mathrm{N}=\mathrm{N}-\mathrm{R}]$ decreases and $\left[\mathrm{ROO}^{\circ}\right]$ rises, with the result that at some instant ( $t=t_{m}$, say) the right hand side of Eq. 2 vanishes exactly. The subsequent course of the reaction is determined by the relative magnitude of $\tau_{a}$ and $\tau_{s}(t)$, but the case of maximum practical interest in the present context is that when $\tau_{a} \gg \tau_{0} \equiv \tau_{s}(0)$. If we confine attention to the time window for which the difference between $\tau_{s}(t)$ and $\tau_{0}$ may be regarded as negligible, the second term on the left hand-side of Eq. 5 represents the change in [ROO $\left.{ }^{\bullet}\right]$ during an interval $\tau_{0}$ that is very short compared to $\tau_{a}$. The steady state approximation amounts to neglecting this small change, and retaining only the first term on the left-hand side of Eq. 5.

$$
\begin{aligned}
{\left[\mathrm{ROO}^{\bullet}\right] } & =\frac{2 \tau_{s}(t)}{\tau_{a}}[\mathrm{R}-\mathrm{N}=\mathrm{N}-\mathrm{R}] \\
& =\frac{2 \tau_{s}(t)}{\tau_{a}}[\mathrm{R}-\mathrm{N}=\mathrm{N}-\mathrm{R}]_{0} \exp \left(-k_{a} t\right) \\
& =\frac{2 \tau_{s}(t)}{\tau_{a}}[\mathrm{R}-\mathrm{N}=\mathrm{N}-\mathrm{R}]_{0}\left(1-k_{a} t\right)
\end{aligned}
$$

The last step follows because the approximation can be guaranteed only for such times which satisfy the condition $k_{a} t<<1$. 
Equations 2-4 can be combined into the equation

$$
\frac{d\left[\mathrm{ROO}^{\bullet}\right]}{d t}=2 k_{a}[\mathrm{R}-\mathrm{N}=\mathrm{N}-\mathrm{R}]+\frac{d}{d t}([\mathrm{P}-\mathrm{H}]+[\mathrm{X}-\mathrm{H}])
$$

On setting the left-hand side to zero, replacing $[\mathrm{R}-\mathrm{N}=\mathrm{N}-\mathrm{R}]$ with $[\mathrm{R}-\mathrm{N}=\mathrm{N}-\mathrm{R}]_{0} \exp \left(-k_{a} t\right)$ and introducing the substitutions

$$
\Sigma(t)=[\mathrm{P}-\mathrm{H}]+[\mathrm{X}-\mathrm{H}] \text { and } \Sigma(0)=[\mathrm{P}-\mathrm{H}]_{0}+[\mathrm{X}-\mathrm{H}]_{0}
$$

one gets

$$
\begin{aligned}
\Sigma(t)= & \Sigma(0)-2[\mathrm{R}-\mathrm{N}=\mathrm{N}-\mathrm{R}]_{0}\left[1-\exp \left(-k_{a} t\right)\right] \\
& \Sigma(0)-2[\mathrm{R}-\mathrm{N}=\mathrm{N}-\mathrm{R}]_{0} k_{a} t \quad\left(k_{a} t<<1\right)
\end{aligned}
$$




\section{Supplementary Figures S1 and S2}

The ORAC Assay: Mathematical Analysis of the Rate Equations and Some Practical Considerations

Juan B. Arellano, Elena Mellado-Ortega, and K. Razi Naqvi

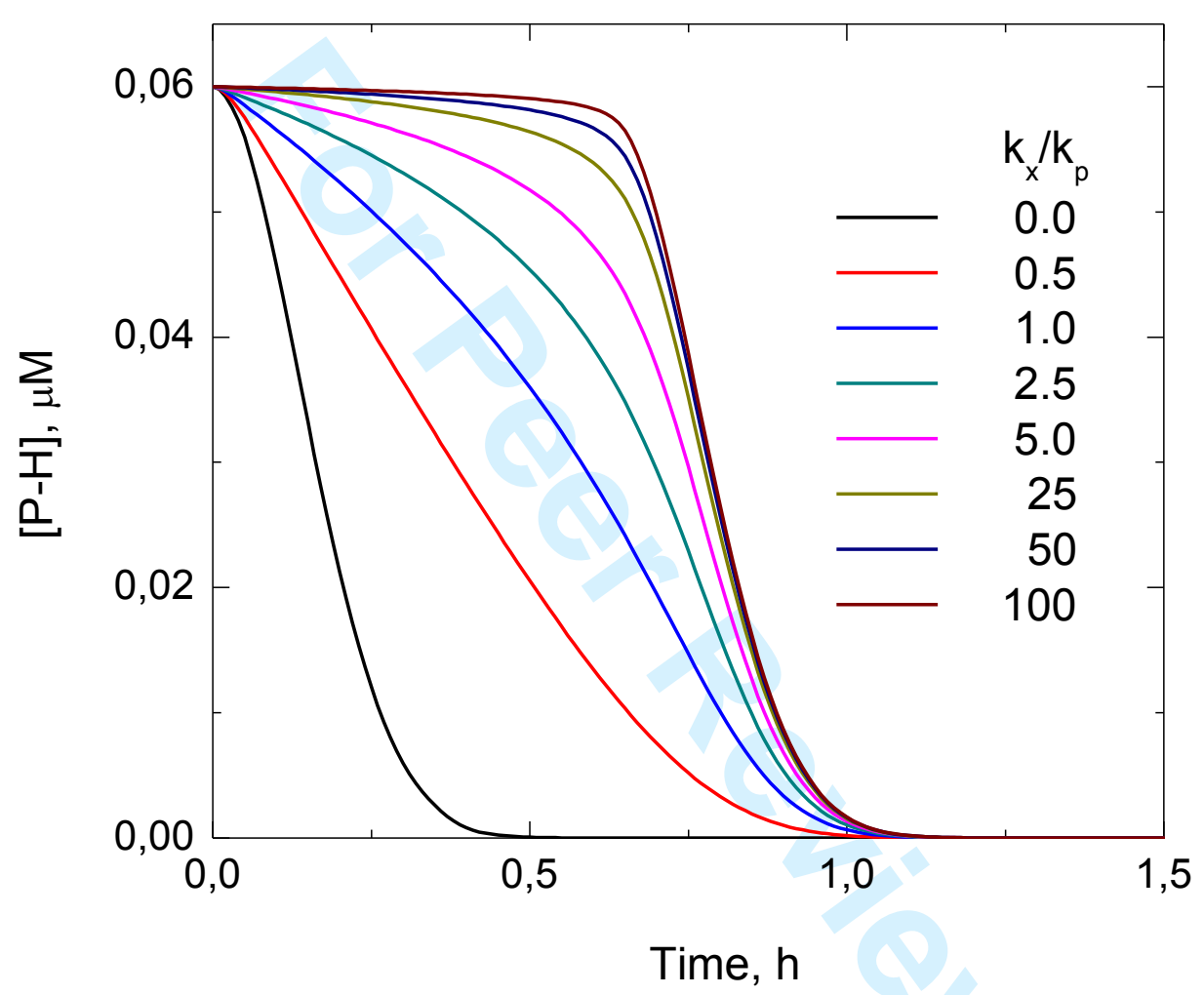

Figure S1. Numerical simulation of the concentration profile of $\mathrm{P}-\mathrm{H}$ over time using different values for the ratio between $k_{p}$ and $k_{x}$. The initial conditions for the starting and intermediate reactants were as follows: $[\mathrm{R}-\mathrm{N}=\mathrm{N}-\mathrm{R}]_{0}=80 \mu \mathrm{M},[\mathrm{P}-\mathrm{H}]_{0}=0.06 \mu \mathrm{M}$, $[\mathrm{X}-\mathrm{H}]_{0}=1 \mu \mathrm{M}$ and $\left[\mathrm{ROO}^{\circ}\right]_{0}=0$. The values for $k_{a}$ and $k_{p}$ were $\sim 2.5 \times 10^{-6} \mathrm{~s}^{-1}$, $10^{4} \mathrm{M}^{-1} \mathrm{~s}^{-1}$ and $k_{x}$ ranged from 0 to $10^{6} \mathrm{M}^{-1} \mathrm{~s}^{-1}$, respectively. 

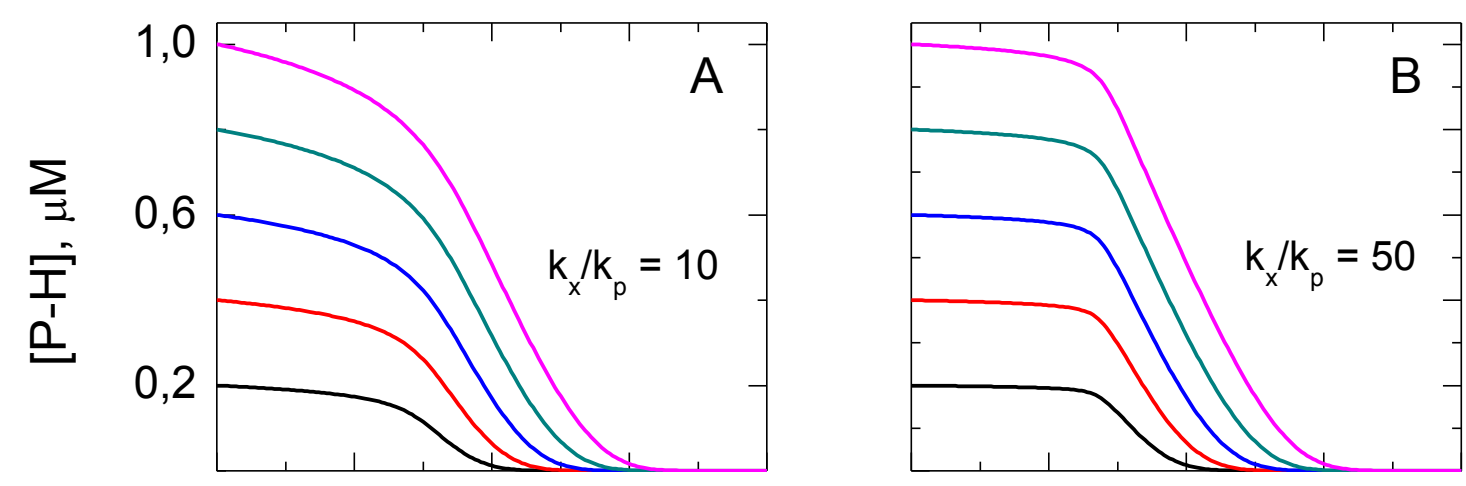

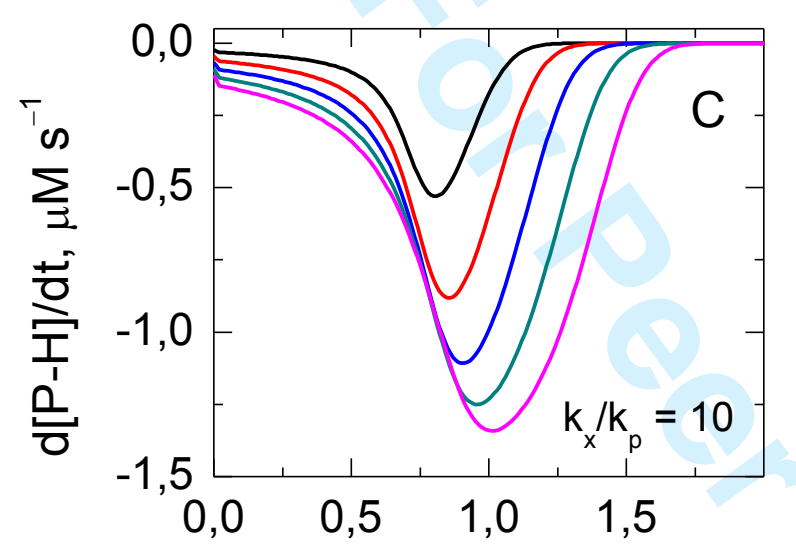

Time, $\mathrm{h}$

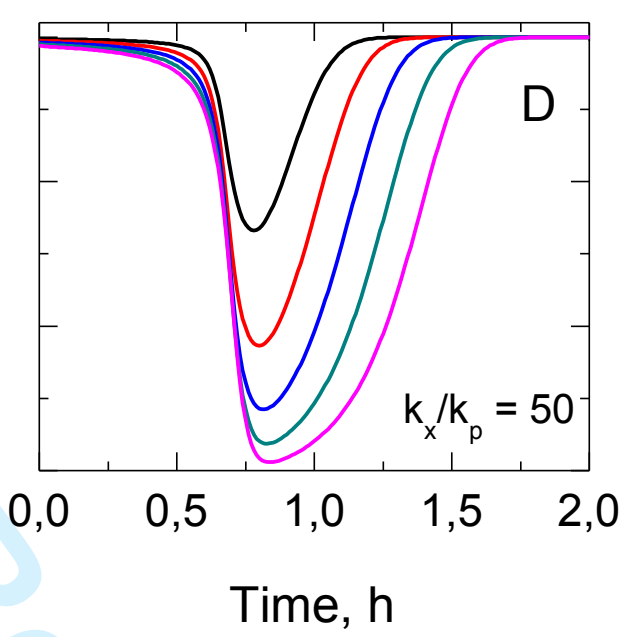

Figure S2. Numerical simulation of the concentration profile (panels A and B) and consumption rate (panels $\mathrm{C}$ and $\mathrm{D}$ ) of $\mathrm{P}-\mathrm{H}$ over time using different ratios between $[\mathrm{X}-\mathrm{H}]_{0}$ and $[\mathrm{P}-\mathrm{H}]_{0}$, and between $k_{p}$ and $k_{x}$. The initial conditions for the starting and intermediate reactants were as follows: $[\mathrm{R}-\mathrm{N}=\mathrm{N}-\mathrm{R}]_{0}=80 \mu \mathrm{M},[\mathrm{P}-\mathrm{H}]_{0}=0.2-1 \mu \mathrm{M}$, $[\mathrm{X}-\mathrm{H}]_{0}=1 \mu \mathrm{M}$ and $\left[\mathrm{ROO}^{\bullet}\right]_{0}=0$. The values for $k_{a}$ and $k_{p}$ were $\sim 2.5 \times 10^{-6} \mathrm{~s}^{-1}$, $10^{4} \mathrm{M}^{-1} \mathrm{~s}^{-1}$ and $k_{x}$ was $10^{5} \mathrm{M}^{-1} \mathrm{~s}^{-1}$ (panels A and C) or $5 \times 10^{5} \mathrm{M}^{-1} \mathrm{~s}^{-1}$ (panels B and D), respectively. 


\section{Response to Reviewer 1}

On behalf of my colleagues I would like to thank Reviewer 1 for his/her critical review. His/her comments clearly indicate the difficulties that dog anyone who attempts a strict and complete analysis of the ORAC kinetic system, particularly when the peroxyl radical self-reaction and alkoxyl radical formation must be included in the kinetic analysis. The difficulties are encountered not only in the mathematical analysis of the ODEs of the ORAC kinetic system, but also in the application of the approximate analytical solution of the ODEs to experimental conditions in standard ORAC assays.

As we stated in our first response to Reviewer 1, our aim, in the first instance, was to find an analytical solution to the minimal ORAC kinetic system. The mathematical analysis has shown how complex the solution of the ODEs of the minimal ORAC kinetic system is despite the apparent simplicity of its reaction scheme, and that the complexity does not evaporate even after the introduction of an approximation. True, our approximate analytical solution of the ODE system of the minimal ORAC kinetic might have little immediate practical use, but it is equally true that, first, our mathematical analysis offers a better understanding of the complex kinetics of the ORAC assay and, second, chemical kineticists can benefit from our mathematical analysis, even if it has merely academic interest at present.

With this premise, we understand that the major effort of our mathematical analysis has to be really focused on the solution of the ODEs of the minimal ORAC kinetic system, making clear that our results have some limitations in the sense that the approximate analytical solution of the ODEs of the minimal ORAC kinetic system cannot be applied to every experimental condition in standard ORAC assays. Even if experimental conditions are adjusted to match perfectly the restrictions of the approximation invoked to solve analytically the ODEs of the minimal ORAC kinetic system, the experimental quantification of some reactants in the ORAC assay still remain challenging during the reaction course. However, experimental quantification of reactants and reaction rates in equivalent chemical systems can be different and so the chemical kineticists studying those systems would make use of our mathematical progress.

In conclusion, our study shows how the ODEs of the minimal ORAC kinetic system can be solved through mathematical analysis, although the solution might have little practical use at present.

Major reservations:

1) We do not disagree in that experimental fluctuations might be overserved in the induction time region of the probe signal over time; however, this is a common situation that chemical kineticists find when they experimentally analyse reaction kinetic systems. So the ORAC kineticists must consequently inspect the experimental data and judge whether a kinetic fitting should be applied.

The initial concentration of the azo compound radical initiator was kept low in our simulations to fulfil one of Reviewer 1's objections. The reaction time in the simulations can be changed easily if the initial concentration of the azo compound radical initiator goes from sub-mM concentrations to $\mathrm{mM}$ concentrations. Nonetheless, the conclusions of our mathematical analysis of the minimal ORAC kinetic system still stand if the side reactions R.4-R.6 are not included in the analysis. 
2) The limitations of the approximate analytical solution of the ODEs of the minimal ORAC kinetic system have been explained in the text. ORAC experiments where the induction time region cannot be clearly distinguished from the decay region are those cases in which the approximate solution of our mathematical analysis has little or no applicability (Tables 1 and 2).

3) Our mathematical analysis of the minimal ORAC kinetic system can be applied only if one antioxidant compound in the assay medium competes with the probe for the peroxyl radical. The mathematical analysis has no application when there are several antioxidant compounds in the reaction mixture.

\section{Abstract. line 7 until line 48}

The abstract has been changed according to Reviewer 1's suggestions.

The term "symmetry reduction" has been included in the abstract to clarify that the ODEs of the minimal ORAC kinetic system cannot be solved by applying Lie symmetry group theory due to the mathematical form of the coefficients of the Chini equation.

\section{P5 line 29}

The expression has been changed.

\section{$\underline{\text { P6 line } 3}$}

The statement has been removed based on the reviewer's view.

\section{$\underline{\text { P6 line } 8}$}

A sentence has been introduced to indicate that the alkoxyl radical self-reaction might be of little relevance in the ORAC assay when the initial concentration of the azo compound radical initiator is kept low.

P6 line 31

The term "Stern-Volmer plots" has been replaced by "Stern-Volmer-like plots"

\section{$\underline{\text { P6 line } 52}$}

We have followed the reviewer suggestion.

An effort has been made to rewrite the last paragraph of the introduction in order to clarify the main purpose of our study while trying keeping its length as short as possible.

\section{$\underline{\text { P7 line } 8}$}

We have followed the reviewer's suggestion.

\section{P7 line 19}


We reached such a conclusion based on the mathematical form of the coefficients and the functional dependence that must exit between them to reduce the non-autonomous Chini equation to the autonomous equation.

$\underline{\text { P7 line } 29 \text { until P8 line } 32}$

An introductory statement has been written to indicate how the approximate analytical solution is evaluated.

The term "mathematical solution" has been corrected in the text. To avoid ambiguity, the first time that "numerical solution" appears, the term is followed by the mathematical method through which the numerical values have been obtained (i.e. Runge Kutta method). Analytical solution is the mathematical function obtained by solving an ODE through mathematics.

In this study, no experiments were carried out in the laboratory; we only performed simulations with numerical and analytical solutions of the ODEs of the minimal ORAC kinetic system. The values of the parameters (i.e. the values for initial concentrations of reactants and rate constants) were in the range described in other ORAC studies. In the first version of the manuscript, we arbitrarily used values for the input parameters that we thought could facilitate a better understanding of our mathematical approach. Reviewer 1 claimed that the analysis was inappropriate because these values were not found in normal ORAC studies. We agreed with Reviewer 1 in this point and all the figures were redone to accommodate values for the initial concentration of the reactants and rate constants employed or determined in other ORAC studies. In our analysis we covered broad ranges and ratios for the values of initial concentrations and rate constants that are perfectly in line with standard ORAC studies. In our simulations, we intentionally started with ratios (between $k_{\mathrm{x}}$ and $k_{\mathrm{p}}$ ) that we knew beforehand to cause a poor match between the numerical and analytical solutions because both bimolecular rate constants were of the same order. We showed how the goodness of the approximation improved when the ratio between $k_{\mathrm{x}}$ and $k_{\mathrm{p}}$ became larger. Figure 4 shows a good match between the numerical and analytical solutions of the ODEs of the minimal ORAC kinetic system. Better overlaps can even be found if the ratios $k_{\mathrm{x}} / k_{\mathrm{p}}$ and $[\mathrm{X}-\mathrm{H}]_{0} /[\mathrm{P}-\mathrm{H}]_{0}$ increase further; however, our intention was not to show a perfect overlap between both numerical and analytical solutions, but to show the way in which the approximate analytical solution improved.

$\underline{\text { P53 line } 37}$

Several papers are included in our study to provide a range of values for the bimolecular rate constant $k_{\mathrm{x}}$ and we use them to provide a "broad" estimation of the range of values for $k_{\mathrm{x}}$ and $k_{\mathrm{x}} / k_{\mathrm{p}}$ we should use as input parameters in the numerical and analytical solutions of the ODEs of the minimal ORAC kinetic system.

Two of them show absolute values for $k_{\mathrm{x}}$ of several antioxidants in different solvents or mixture of solvents, some of them containing water (Slavova-Kazakova et al 2015; Neta et al 1989). In these two papers, the range of values for $k_{\mathrm{x}}$ is rather broad and goes from $10^{4} \mathrm{M}^{-1} \mathrm{~s}^{-1}$ to $10^{8} \mathrm{M}^{-1} \mathrm{~s}^{-1}$ and the dependence of $k_{\mathrm{x}}$ on the solvent mixture are also investigated: For example, $k_{\mathrm{x}}$ for Trolox with $\mathrm{CCl}_{3} \mathrm{O}_{2}{ }^{\bullet}$ in aqueous iso-propanol or dioxane changes from $\sim 6 \times 10^{8} \mathrm{M}^{-1} \mathrm{~s}^{-1}$ in nearly pure water to $\sim 2 \times 10^{7} \mathrm{M}^{-1} \mathrm{~s}^{-1}$ in the neat organic solvent. 
Four of them give relative reactivity $\left(k_{\mathrm{x}} / k_{\mathrm{p}}\right)$ of antioxidants in aqueous buffer where $k_{\mathrm{x}}$ is of similar order to, or 2-2.5 orders of magnitude larger than, that of $k_{\mathrm{p}}$ (LópezAlarcon and Lissi 2005, Pino and Lissi 2001, Kohri and Fujii 2009, Ramos et al 2016).

\section{P9 question}

We have numbered reactions as R.1, R.2, etc., but equations as Eq.1, Eq.2, etc..

\section{P10 line 31}

Done.

\section{$\underline{\text { P10 line } 39}$}

The sentence has been rewritten to indicate that the flatness becomes less prominent when the ratio $[\mathrm{X}-\mathrm{H}]_{0} /[\mathrm{P}-\mathrm{H}]_{0}$ decreases and, particularly, $k_{x}$ and $k_{p}$ are of similar order of magnitude.

\section{P11 paragraph 1}

We do not assume as Reviewer 1 has stated in his/her comment that in the ORAC reaction only $\mathrm{X}-\mathrm{H}$ is being consumed during the induction phase, that the induction phase ends when $\mathrm{X}-\mathrm{H}$ is consumed, and only...

Figure S2 was drawn to show how the concentration profile and the consumption rate of $\mathrm{P}-\mathrm{H}$ evolve over time. In the four panels one can see how $\mathrm{P}-\mathrm{H}$ is consumed in both the induction time and kinetic regions, although the changes are more noticeable in the induction time region when the ratios $[\mathrm{X}-\mathrm{H}]_{0} /[\mathrm{P}-\mathrm{H}]_{0}$ and $k_{\mathrm{x}} / k_{\mathrm{p}}$ are smaller.

\section{$\underline{\text { P11 line } 31}$}

This sentence was included in the manuscript after receiving the first round of comments raised by Reviewer 1, where (s)he stated that "At low AOX concentration, contact with the probe in time (<radical lifetime) is not guaranteed, ...". In our response, we established a peroxyl radical lifetime of about $100 \mathrm{~s}$, assuming that the self-reaction of tertiary peroxyl radicals is $10^{4} \mathrm{M}^{-1} \mathrm{~s}^{-1}$ (Ingold, 1969) and the peroxyl radical concentration was in the (sub) $\mu \mathrm{M}$ range in the reaction mixture. So, if the reactions R.4-R.6 are negligible in our analysis, $[\mathrm{P}-\mathrm{H}]$ must simply decrease with a reaction rate that depends on the instant concentration of $\mathrm{P}-\mathrm{H}$ and the peroxyl radical. To avoid any further misconception here, the last part of the sentence has been removed.

\section{$\underline{\text { P11 line } 43}$}

Our main purpose and goal was to know the mathematical functions that govern the concentration profile of reactants over time and its dependence on the input parameters.

\section{$\underline{\text { P12 line } 25}$}

In the instructions for authors there is no specific instruction about how reactions and equations should be numbered.

\section{$\underline{\text { P15 line } 25}$}


Finding the analytical solution of the ODEs of the minimal ORAC kinetic system has not been an easy task, and it is our hope, earnest as well as confident, that our effort will provide some insight even to those chemical kineticists who are dealing with other, similar chemical systems.

$\underline{\text { P18 line } 40}$

The sentence has been rewritten to clarify that deviations might be expected between Eq.13 and experimental data beyond the point where $[\mathrm{P}-\mathrm{H}]$ and $[\mathrm{X}-\mathrm{H}]$ are consumed. In this particular case, ROO is continuously produced, but not consumed by $\mathrm{P}-\mathrm{H}$ and $\mathrm{X}-\mathrm{H}$; consequently, R00• can reach concentration values for which the reactions R.4-R.6 are not any more negligible.

In our model, the simulations show a good fit between the numerical and analytical solutions of the ODE of the minimal ORAC kinetic system if R.4-R.6 are not invoked.

$\underline{P 19}$

Here we do not understand the reviewer comment. Here (s)he states that "This section cannot be validated until complete information showing that different data has been used for the kinetic model and the analytical solution."

As explained above (P53 line 37) and indicated in the text of the manuscript, our approximation was validated by comparing the analytical solution of the ODE of the minimal ORAC kinetic system that we achieved with the numerical solution of the same ODEs using the Runge Kutta method. In order to compare both numerical and analytical solutions the same input parameters were used.

The input parameters (i.e. the initial concentrations of reactants and rate constants) were obtained from several papers, but these papers were used simply to establish ranges for the values of the initial concentration of reactants and bimolecular rate constants. This allowed us to perform simulations under theoretical conditions that were not in fact far from experimental conditions. So, our model simply inspects the approximate analytical solution of the minimal ORAC kinetic system without invoking R.4-R.6 and using input parameters with order of magnitudes that are in line with those reported in normal ORAC assays.

$\underline{\mathrm{P} 21}$

The final conclusion of the manuscript has been rewritten to indicate that the approximate analytical solution is of academic interest and its applicability to normal ORAC assay might be of limit use due to the restrictions imposed to solve the ODEs through mathematical analysis.

$\underline{\text { Table } 2}$

In the table we submitted to IJCK there is a vertical column between $k_{\mathrm{x}} / k_{\mathrm{p}}$ and the remaining columns. We do not understand why Reviewer 1 does not see it. 